\title{
A Systems Approach to Conduct an Effective Literature Review in Support of Information Systems Research
}

\author{
Yair Levy and Timothy J. Ellis \\ Graduate School of Computer and Information Sciences, \\ Nova Southeastern University, Florida, USA
}

\author{
levyy@nova.edu ellist@nova.edu
}

\begin{abstract}
This paper introduces a framework for conducting and writing an effective literature review. The target audience for the framework includes information systems (IS) doctoral students, novice IS researchers, and other IS researchers who are constantly struggling with the development of an effective literature-based foundation for a proposed research. The proposed framework follows the systematic data processing approach comprised of three major stages: 1) inputs (literature gathering and screening), 2) processing (following Bloom's Taxonomy), and 3) outputs (writing the literature review). This paper provides the rationale for developing a solid literature review including detailed instructions on how to conduct each stage of the process proposed. The paper concludes by providing arguments for the value of an effective literature review to IS research.
\end{abstract}

Keywords: Literature review, effective literature review, literature search, literature categorization, literature classification, literature analysis, literature synthesis, doctoral education.

\section{Introduction}

A methodological review of past literature is a crucial endeavor for any academic research (Webster \& Watson, 2002, pp. 48-49). The need to uncover what is already known in the body of knowledge prior to initiating any research study should not be underestimated (Hart, 1998). Some fields of studies, such as engineering, have chronically suffered from a lack of proper literature reviews, which has hindered theoretical and conceptual progress (D. Shaw, 1995). Webster and Watson (2002) also criticized the Information Systems (IS) field for having very few theories and outlets for quality literature review. Moreover, they noted that the IS field may greatly benefit from effective methodological literature reviews that are "... strengthening IS as a field of study" (Webster \& Watson, 2002, p. 14). In light of these considerations, the central aim of this study is to address the issue of developing an effective literature review by proposing a systematic ap-

Material published as part of this journal, either online or in print, is copyrighted by the publisher of the Informing Science Journal. Permission to make digital or paper copy of part or all of these works for personal or classroom use is granted without fee provided that the copies are not made or distributed for profit or commercial advantage AND that copies 1) bear this notice in full and 2) give the full citation on the first page. It is permissible to abstract these works so long as credit is given. To copy in all other cases or to republish or to post on a server or to redistribute to lists requires specific permission and payment of a fee. Contact Editor@inform.nu to request redistribution permission. proach that will guide the researcher on such a daunting task.

This paper is divided into four main sections. The rest of this introductory section will address what a literature review is and why a literature review is crucial for research. The following three sections will review the three steps of the proposed systematic approach for literature review. Section two will address the literature review 
inputs including: ways to find applicable literature, qualifying the literature, ways to read research literature, and how to know that one is done with the literature search. The third section will review the proposed process for analyzing, synthesizing, and evaluating the literature. The final section addresses the output step of this systematic process by proposing an approach to writing the actual literature review following the theory of argument.

\section{What is a Literature Review?}

Novice researchers tend to approach the literature review as nothing more than a collection of summaries of papers or an elaborated annotated bibliography of multiple research manuscripts (Webster \& Watson, 2002). A meaningful literature review is much more. Hart (1998) defined the literature review as "the use of ideas in the literature to justify the particular approach to the topic, the selection of methods, and demonstration that this research contributes something new" (p. 1). He also noted that for the literature review, "quality means appropriate breadth and depth, rigor and consistency, clarity and brevity, and effective analysis and synthesis" (Hart, 1998, p. 1). J. Shaw (1995) noted that the process of the review should "explain how one piece of research builds on another" (p. 326). Webster and Watson (2002) defined an effective literature review as one that "creates a firm foundation for advancing knowledge. It facilitates theory development, closes areas where a plethora of research exists, and uncovers areas where research is needed" ( $p$. 13). From these definitions it is clear that an effective literature review should include the following characteristics: a) methodologically analyze and synthesize quality literature, b) provide a firm foundation to a research topic, c) provide a firm foundation to the selection of research methodology, and d) demonstrate that the proposed research contributes something new to the overall body of knowledge or advances the research field's knowledge-base.

\section{Stages of the literature review process}

This paper presents the literature review process in a systematic way following the "inputprocessing-output" approach. "Process" is defined in the context of this work as sequential steps of activities (Sethi \& King, 1998). Thus, following the description of what constitutes an effective literature review combined with the definition of process proposed here, this study defines literature review process as: sequential steps to collect, know, comprehend, apply, analyze, synthesize, and evaluate quality literature in order to provide a firm foundation to a topic and research method. Moreover, the output of the literature review process should demonstrate that the proposed research contributes something new to the overall body of knowledge. The term body of knowledge (BoK) refers to the cumulative research-supported knowledge achieved by "building on each other's [research] results" (Iivari, Hirschheim, \& Klein, 2004, p. 314). Following this approach, the current paper suggests a three-step literature review process to guide novice researchers on the development of a sound and effective literature review. The three steps of the proposed literature review process are: 1) Inputs, 2) Processing, and 3) Outputs. Figure 1 provides an overall view of the process proposed. The following three sections of this paper (2. Literature Review: Inputs; 3. Literature Review: Processing; 4. Literature Review: Outputs) are organized to follow the three main steps in the proposed effective literature review process.

\section{What is unique about an IS- related literature review?}

Although the literature review process proposed in this paper may be generalized to any field of social and behav-

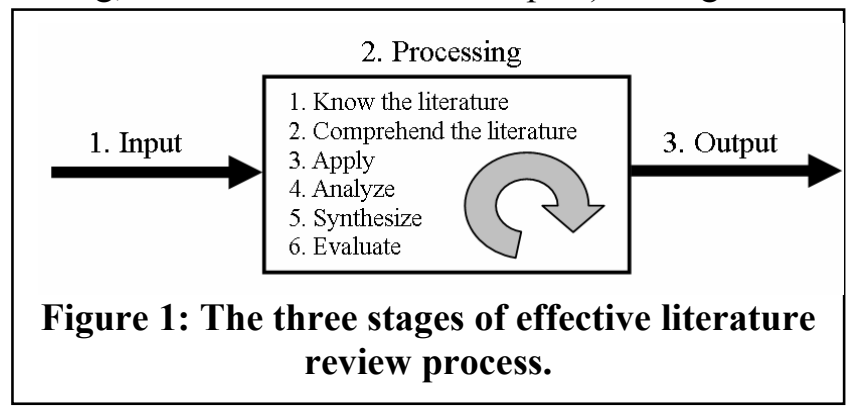


ioral science, it is especially applicable to the challenges inherent in information systems research. The IS "literature universe" is comprised of diverse, interdisciplinary work (Webster \& Watson, 2002) which may lead novice researchers to concentrate in limited disciplinary sources when conducting their literature foundations search, while missing some very fruitful work conducted in another sub-discipline within the IS research literature. For example, if a novice IS researcher uses a particular source (i.e. a given literature database from a particular vendor) the universe of literature explored is limited. Instead, an effective literature search in the IS-related literature must exhaust all sources that contain IS research publications (i.e. journals, quality conference proceedings, etc.) that are valid to the proposed study. Thus, the work presented here will provide discussions on issues related to common pitfalls when attempting to seek quality IS research literature.

There is, finally, a great deal of IS literature of varying quality. Such a large number of electronic and print sources are available that the novice researcher can be overwhelmed in determining which sources contain accurate, valid information. It is important to address approaches on where and how to locate quality IS literature.

\section{Why Conduct a Literature Review?}

Before examining how to conduct a literature review, one must first understand the place of the review in research (Webster \& Watson, 2002). Thus, two questions must be answered: What is research? Why is a literature review needed for any quality research endeavor?

Research is defined as an endeavor that scholars "intentionally set out to enhance [their] understanding of a phenomenon and expect to communicate what [they] discover to the large scientific community" (Leedy \& Ormrod, 2005, p. 4). Two critical considerations stem from this definition: a) research must enhance the scientific community's current understanding of a phenomenon, or contribute to enhance the BoK, and b) research must communicate what was discovered in the new study to the scientific community. Knowing the current status of the BoK in the given research field is an essential first step for any research project (Iivari et al., 2004). An effective literature review accomplishes this step by:

1. Helping the researcher understand the existing body of knowledge including where excess research exists (i.e. what is already know?) and where new research is needed (i.e. what is needed to be known?)

2. Providing a solid theoretical foundation for the proposed study (related to "what is already known?")

3. Substantiating the presence of the research problem (related to "what is needed to be known?")

4. Justifying the proposed study as one that contributes something new to the BoK

5. Framing the valid research methodologies, approach, goals, and research questions for the proposed study

The next three sub-sections address the importance of the literature review for quality IS research.

\section{Build a solid theoretical foundation for your study}

Developing a solid foundation for a research study is enabled by a methodological analysis and synthesis of quality literature (Barnes, 2005; Webster \& Watson, 2002). One of the main reasons for conducting the literature review is to enable researchers to find out what is already known. However, it is important to remember that not everything reported in the literature is of equal rigor (Ngai \& Wat, 2002). When proposing a new study or a new theory, researchers should en- 
sure the validity of the study and reliability of the results by making use of quality literature to serve as the foundation for their research (Barnes, 2005). Quality literature stimulates additional research studies, thus providing validation of the original theory proposed (Barnes, 2005). Straub (1989) noted that "with validated instruments, researchers can measure the same research constructs in the same way, granting improved measurement of independent and dependent variables, and in the long run, helping to relive the confounding that plagues many streams of MIS literature" (p. 148). Building a solid theoretical foundation based on quality resources enables researchers to better explain as well as understand problems and solutions that address actual issues with which practitioners are struggling.

Conducting an effective literature review that will yield a solid theoretical foundation should also provide a firm foundation to the selection of the methodology for the study (Ngai \& Wat, 2002). The selection of the methodology should not be interpreted as placing more rigor on one type of research such as qualitative, quantitative, exploratory or confirmatory, but rather it should enable the researcher to understand what methodologies were previously validated (Straub, 1989). Thus, a solid theoretical foundation should also provide researchers the justifications for a given methodology and enable them to provide justifications for why a given approach is optimal for their study.

\section{Fitting the literature into your research}

An effective and quality literature review is one that is based upon a concept-centric approach rather than chronological or author-centric approach (Webster \& Watson, 2002). Bem (1995) noted that "authors of literature reviews are at risk for producing mind-numbing lists of citations and findings that resemble a phone book - impressive case, lots of numbers, but not much plot" (p. 172). Thus, researchers must continuously ask themselves when reviewing literature and when writing the literature review: 'how is the work presented in the article I read related to my study?' Answering this question will allow researchers to tie the literature into their own study. Moreover, during the review of the literature researchers should utilize sources that substantiate the presence of the problem under investigation (Barnes, 2005). Doing so will enable the researcher to provide a solid argument for the need for their study as well as spot where literature fits into their own proposed study. Moreover, use of literature should provide the grounds for legitimization of the research questions proposed in the study as well as validate the approach proposed by the study.

\section{Place your study in the context of existing work (body of knowledge)}

Aside from the need to fit a given article into the proposed study, researchers should also address the first of their proposed study in the context of the BoK. As noted above, one of the main definitional components of research is the ability to add to the current BOK. As such, quality research must provide justifications for the potential contributions provided by the proposed study. Such justifications should demonstrate how the proposed research contributes something new to the overall BoK or advances the research field's knowledge. A classic example of this approach is the DeLone and McLean's (1992) paper that noted "the importance of defining the IS dependent variable cannot be overemphasized... in recognition of this importance, this paper explores the research that has been done... and attempts to synthesize this research into a more coherent body of knowledge" (p. 61). The evidence in the contribution of the classical DeLone and McLean's (1992) to the BoK was materialized by the stream of research studies conducted following this paper and was summarized again by them over a decade later (DeLone \& McLean, 2003). 


\section{Literature Review: Inputs}

This section will address key issues related to the process of understanding what quality IS literature is as well as the process of gathering manuscripts for an effective literature review, the two parts of the "inputs" stage. In any systematic approach, if the system input is either incorrect, of low quality, or irrelevant, the resulted output is going to be ineffective regardless of the quality of the processing stage or, colloquially, garbage-in/garbage-out. Webster and Watson (2002) noted that "a systematic search should ensure that you accumulate a relatively complete census of relevant literature" (p. 16). In order to avoid the pitfall of garbage-in/garbage-out and produce an effective literature review, this section will start by addressing issues related to the quality of literature for the review. The discussion will address some common errors of novice IS researchers as well as provide resources on where to find quality IS literature. Subsequently, this section will provide specific approaches on how to perform a quality literature search by elaborating on the technique introduced by Webster and Watson (2002) with specific examples. The section then examines how to read research literature for the review, and concludes with a discussion of how to determine when the literature search is approaching completion.

\section{Where to Look for Quality IS Literature?}

Sir Isaac Newton (1676) noted "if I have seen a little further it is by standing on the shoulders of giants". Clearly, researchers who are able to take advantage of knowledge and discoveries of other researchers will be able to expand the BoK further. However, 'standing on the shoulders of midgets' will not provide much of a horizon for the novice IS researcher to produce quality work. The quality of the literature used plays a significant role in advancing the knowledge of the researcher and the overall BoK. The novice IS researcher often finds it difficult to determine the quality of literature. This section is aimed at providing novice IS researchers some tools to understand the quality of IS literature they are reading.

\section{Validating the quality of IS literature}

The significance of academic research work is materialized when it is published (Davison, Vreede, \& Briggs, 2005). As such, the academic research community implemented the peerreview process as a mechanism to control quality and eliminate flaws prior to publication of research manuscripts (Davison et al., 2005). The use of the peer-review process is essential as it ensures that researchers can "use published work with confidence, and use the works of others as stepping stones and corner stones for advancing new concepts and insights" (Davison et al., 2005, p. 969). It is important to note, however, that all published material is not equal in quality. This problem is especially troublesome in the IS field where descriptions and discussions of new technology often appears in non-refereed work or in questionable sources. The problem is exacerbated by the presence of corporate sponsorship and its impact on research findings (Hozack, Ranawat, \& Rothman, 2003). Thus, when looking for quality IS research literature, special attention should be made for any work that is not peer-reviewed or is practitioners oriented. Although not totally unacceptable, use of such sources (i.e. professional magazines, newspapers, etc.) should be restricted to factual information due to the low theoretical background and application dependency. Therefore, quality IS research literature from leading, peer-reviewed journals should serve as the major base of literature review as it provides sufficient theoretical background as well as leads for additional references on the specific subject matter.

Fortunately, IS scholars are continuously conducting analyses of the quality of IS literature (Saunders, n.d.) and an extensive list of the highly ranked MIS journals is available from ISWorld.org (Hardgrave \& Walstrom, 1997; Katerattanakul, Han, \& Hong, 2003; Lowry, Romans, \& Curtis, 2004; Mylonopoulos \& Theoharakis, 2001; Peffers \& Ya, 2003; Rainer \& Miller, 2005; Walstrom, Hardgrave, \& Wilson, 1995; Whitman, Hendrickson, \& Townsend, 1999). Figure 2 


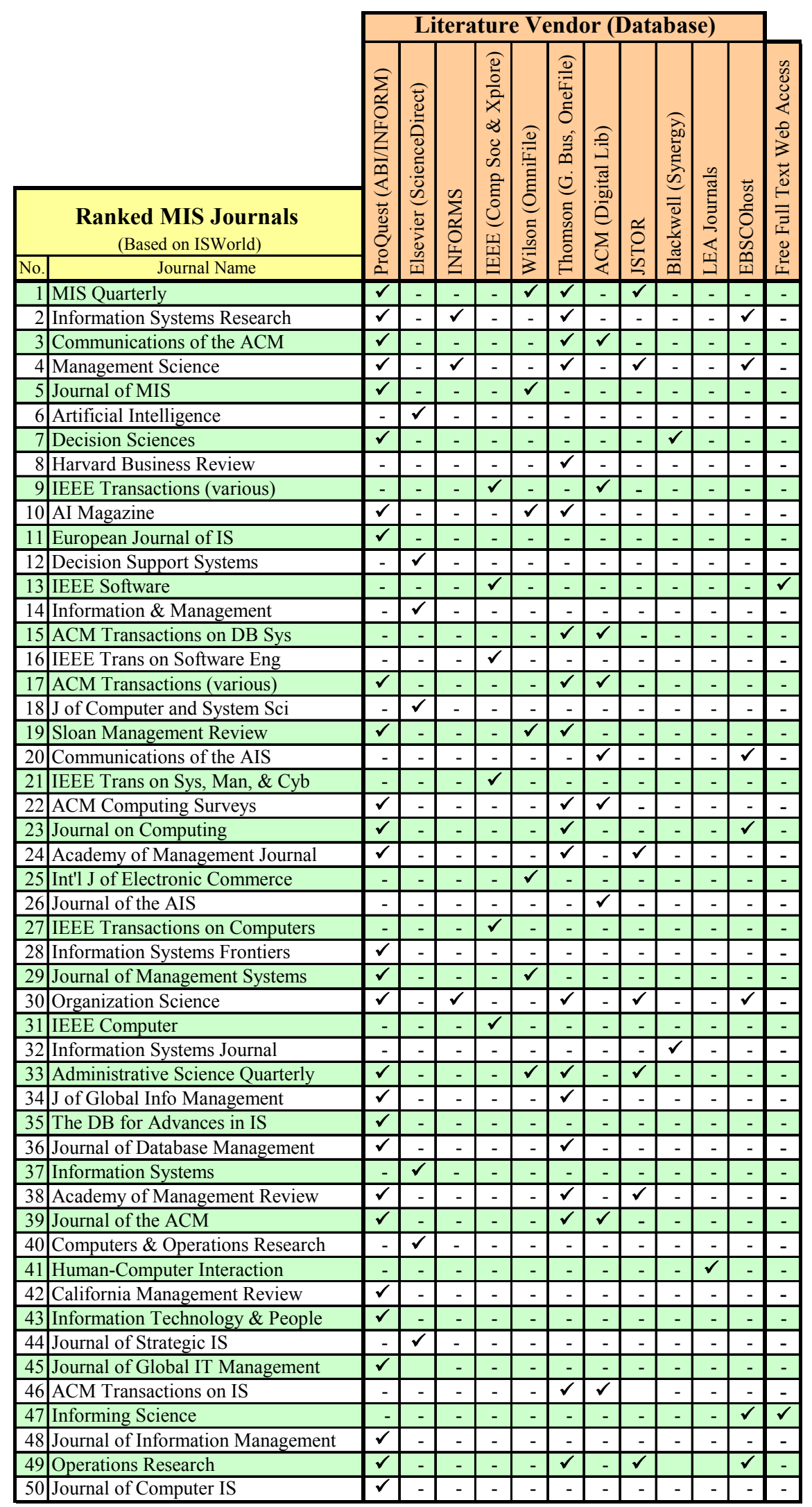

Figure 2: ISWorld's top 50 ranked MIS journals and electronic availability 
provides a list of the top 50 ranked MIS journals based on the list generated by Saunders (n.d.) for ISWorld. Culnan (1978) noted that availability to research articles is critical to the development of IS as a field. Thus, Figure 2 also provides information on electronic availability of each of the journals in the list.

One main intention to add such electronic availability is to help novice IS researchers to understand the diverse resources and outlets where quality IS articles can be found. The columns under "literature Vendor (database)" in Figure 2 represent the names of vendors that offer articles from a given journal in their database. The check mark under a specific vendor/database indicates that this vendor offers either in full text or abstract and citation of such journal articles, but note that some limitations on availability (i.e. embargo years) may exist.

Webster and Watson (2002) commented on conference proceedings, indicating that IS researchers "should also examine selected conference proceedings, especially those with a reputation for quality" (p. 16). Although conferences are valuable scientific venues for exchange of ideas and a major incubator for new research agendas, the overall rigor of conference proceedings is lower than one found in leading journals (Culnan, 1978). Moreover, there appears to be a growing number of conferences that are purely for-profit and run by questionable organizations (Sorenson \& Fleming, 2004). As such, proceedings from these for-profit conferences may not have been subjected to the same peer-review process as those from conferences run by reputable research/professional associations (i.e. AIS, ACM, INFORM, IEEE, AOM, ISI, DSI, etc.). Thus,

\begin{tabular}{|c|c|c|c|c|c|c|c|c|}
\hline & \multicolumn{4}{|c|}{$\begin{array}{c}\text { Literature } \\
\text { Vendor } \\
\text { (Database) }\end{array}$} & \multirow{4}{*}{ 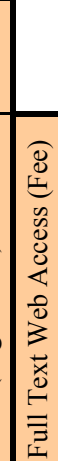 } & \multirow{4}{*}{ 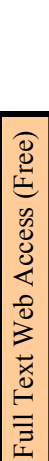 } & \multirow{4}{*}{ 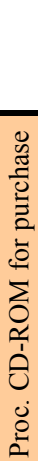 } \\
\hline & & \multirow{3}{*}{ 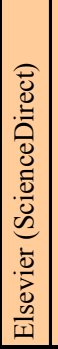 } & \multirow{3}{*}{ 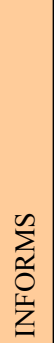 } & \multirow{3}{*}{ 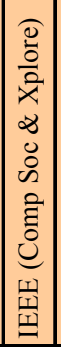 } & \multirow{3}{*}{ 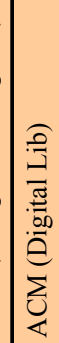 } & & & \\
\hline & $\begin{array}{l}\text { Ranked and Non-Ranked IS Conferences } \\
\text { Ranked Order is Based on Hardgrave and Walstorm (1997) }\end{array}$ & & & & & & & \\
\hline No. & Conference Name & & & & & & & \\
\hline & International Conference on Information Systems (ICIS) & - & - & - & $\checkmark$ & - & - & - \\
\hline 2 & Hawaii International Conference on System Sciences (HICSS) & - & - & $\checkmark$ & - & - & $\checkmark$ & - \\
\hline 3 & International Federation for Information Processing (IFIP) & - & - & - & $\checkmark$ & $\checkmark$ & - & $\checkmark$ \\
\hline 4 & International Conference on Decision Support Systems (DSS) & - & - & - & $\checkmark$ & - & - & - \\
\hline 5 & Decision Sciences Institute (DSI) - National Conference & - & - & - & - & $\checkmark$ & - & - \\
\hline 6 & Society of Information Management (SIM) Conference & $\checkmark$ & - & - & - & - & - & - \\
\hline & $\begin{array}{l}\text { International Association for Computer Information Systems (IACIS) Conference } \\
\text { (Proceedings published in Issues in Information Systems) }\end{array}$ & - & - & - & - & $\checkmark$ & - & $\checkmark$ \\
\hline 8 & $\begin{array}{l}\text { Institute for Operations Research and the Management Sciences (INFORMS) } \\
\text { Conference }\end{array}$ & - & $\checkmark$ & - & - & - & - & - \\
\hline 9 & Information Resources Management Association (IRMA) Conference & - & - & - & - & - & - & $\checkmark$ \\
\hline 10 & Academy of Management (AOM) Conference & - & - & - & - & $\checkmark$ & - & - \\
\hline 11 & Decision Sciences Institute (DSI) - Regional Conferences & - & - & - & - & $\checkmark$ & - & $\checkmark$ \\
\hline $\mathrm{NR}$ & International Academy of Information Management (IAIM) Conference & - & - & - & - & $\checkmark$ & - & $\checkmark$ \\
\hline $\mathrm{NR}$ & American Conference on Information Systems (AMCIS) & - & - & - & $\checkmark$ & - & - & - \\
\hline $\mathrm{NR}$ & Information Systems Education Conference (ISECON) & - & - & - & - & - & $\checkmark$ & $\checkmark$ \\
\hline $\mathrm{NR}$ & Institute of Electrical and Electronics Engineers (IEEE) National Conferences & - & - & $\checkmark$ & - & - & - & - \\
\hline $\mathrm{NR}$ & Informing Science + Information Technology Education (InSITE) Conference & - & - & - & - & - & $\checkmark$ & $\checkmark$ \\
\hline
\end{tabular}

Figure 3: Ranked and non-ranked IS conferences with electronic availability of proceedings 
novice IS researchers should attempt to limit the use of conference proceedings to those they found referenced in articles from quality IS journals or ones list in Figure 3. Unfortunately, unlike IS journal articles where studies were done and resources are available to indicate some level of quality, there appears to have been very little attention given to the development of similar rankings for IS conference proceedings (C. S. Saunders, personal communication, February 9, 2006). Hardgrave and Walstrom (1997) reported a list of top IS conferences as part of their general quest for reputable outlets of IS research. Although providing an important insight, their ranking was based on faculty members' perceptions of how valuable each conference in general is to the MIS field, and no specific indications or measures were done for the quality of these conferences' proceedings. Moreover, Hardgrave and Walstrom's study was done about a decade ago and over that time new IS-related conferences sponsored by reputable associations have immerged. Thus, additional work should be done to generate a ranked list of IS conference proceedings similar to the ranking process done for IS journals noted above. Having said that, proceedings from these reputable IS conferences are certainly valid for IS research (Webster \& Watson, 2002).

Figure 3 provides the top eleven ranked IS conferences as reported by Hardgrave and Walstrom (1997). Additionally, non-ranked IS conferences that appear to be valuable for IS scholars were added to the list. As noted before, more work is needed to validate this list.

\section{Testing for applicability to your study}

While searching for quality literature is essential, it is also important to identify articles that are applicable to the proposed study. The issue of testing for applicability of research literature to the proposed study has two critical facets. The first deals with the inclusion or exclusion of articles from the literature review, and the second deals with ethical and unethical use of references. Both facets should be addressed during the literature search and gathering process to ensure high quality and effective literature review.

Applicability of literature: Occasionally research studies attempt to combine several theories, constructs, and/or models (see additional discussions about this under the "Apply the Literature" below). As such, a literature review for each stream of theory or construct may be relevant. In such cases, one may find numerous studies on a specific theory, model, or framework. Thus, deciding which piece of literature should be included as part of the literature review can be a daunting task for novice researchers. One common example is the extensive work done on the Technology Acceptance Model (TAM) by Davis (1989) and colleagues (Davis, Bagozzi, \& Warshaw, 1989; Venkatesh \& Davis, 1996, 2000). When novice IS researchers produce a search on TAM related constructs, they encounter numerous studies. At that point, novice IS researchers tend to ask themselves: should all studies and articles dealing with that theory, model, and/or construct be included in my review? The approach advocated here is: no, each literature piece should constantly be evaluated on how applicable it is to the proposed study. If an article or study is only remotely relevant, it may be used as a support for a particular argument, but should not be used as foundation literature to the proposed study. Thus, only the applicable literature articles that are relevant to build the theoretical foundations for the validity of the theories, constructs, and measures should be noted. Clearly the key fundamental studies that established the validity and reliability of these theories, constructs, and measures are cornerstones for the discussions and must be included, like Davis (1989), Davis et al. (1989), and Venkatesh and Davis $(1996,2000)$ are key for a TAM review.

Ethical and unethical use of references: Ethical behavior has been a concern for IS scholars (Couger, 1989). Ethical behavior is defined as "being in accordance with rules or standards for right conduct or practice" (Laband \& Piette, 2000, p. 24). Unethical behavior constitutes a violation of such conduct or practice. The accurate and valid use of literature should be maintained to the highest ethical standard (Kock, Davison, Clarke, \& Loch, 2000). Unethical use of references 
includes taking material out of context or even intentional misstatements (Laband \& Piette, 2000; Mason, Bearden, \& Richardson, 1990). Such unethical behavior eventually leads to a major devastation to these scholars' career, while eroding the credibility of the IS field as a quality research (Kock et al., 2000). Thus, in order to maintain the integrity of the IS field and protect individual reputation, IS researchers must ensure that references used in a proper context and with high degree of confidence.

\section{How to Find Quality IS Literature?}

A literature search is the process of querying quality scholarly literature databases (i.e. ABI/INFORM ${ }^{\circledR}$, JSTORE $^{\circledR}$, Elsevier $^{\circledR} /$ ScienceDirect $^{\circledR}$, WilsonWeb ${ }^{\circledR}$, etc.) in order to gather applicable research manuscripts related to the phenomenon under investigation. It is at this stage that many novice researchers struggle with locating appropriate quality sources to query. Webster and Watson (2002) suggested that "the major contributions are likely to be in the leading journals. It makes sense, therefore, to start with them ... [researchers] should also examine selected conference proceedings, especially those with a reputation for quality" (Webster \& Watson, 2002, p. 16). Thus, it is the aim of this section to provide guidelines on how IS researchers should initiate and conduct an effective literature search. Moreover, due to the interdisciplinary nature of IS literature and the diversification of IS literature outlets, this section will also address issues related to the various literature database and electronic resources. Additionally, this section will provide details on several techniques to help novice researchers, in particular IS novice researchers, conduct a more effective literature search. Moreover an attempt will be made to focus such discussion specifically in the context of IS research.

\section{Literature databases \& electronic resources}

With the increased use of electronic resources for library services, the speed at which researchers can find relevant literature increased dramatically (D. Shaw, 1995). However, novice researchers should be fully competent in using such electronic resources in order to produce an effective literature review. As noted previously, one common mistake of novice researchers is attempting to exhaust a literature search using one or two literature database vendors (i.e. ABI/INFORM ${ }^{\circledR}$, JSTORE $^{\circledR}$, Elsevier ${ }^{\circledR} /$ ScienceDirect $^{\circledR}$, WilsonWeb ${ }^{\circledR}$, etc.), primarily using a keyword search approach. This method leads to two main limitations: a) very narrow literature background, and $b$ ) shallow depth of literature background.

The narrowness of the literature background is in terms of the number of journals or other resources used. By using one or two vendors in the literature search process, the literature revealed is limited to only the journals and electronic resources provided by such vendors. This narrowness of searching can cause a novice researcher to obtain only partial knowledge about a phenomenon. This problem is particularly acute in the IS domain due to the large dispersion of quality IS literature over hundreds of databases and numerous literature vendors. It is important for the novice researchers, particularly novice IS researchers, to spend time expanding their literature seeking skills beyond a given vendor, learning how to conduct a literature search utilizing multiple literature database vendors' resources.

Webster and Watson (2002) noted that "a systematic search should ensure that you accumulate a relatively complete census of relevant literature" (p. 16). Thus, the next three sections provide additional details on specific techniques to be used when conducting an effective literature search. The first technique is meaningful keyword searching, followed by backward searching, and finishing with forward searching. Mastering all three techniques is key for novice IS researchers. due to the diversification and multidisciplinary nature of IS literature in order to exhaust all literature sources on specific phenomenon, one must be able to utilize all techniques in order to obtain a wide literature background. Likewise, using all such techniques together should ensure that 
novice IS researchers do not fall into the trap of limited depth of literature background that results from using only IT buzzwords.

\section{Keywords search}

Keyword search refers to the querying of quality scholarly databases by the use of a specific word or phrase (i.e. "keyword") when attempting to find relevant literature. Keywords can be searched against several categories such as the documents' keywords, title, and abstract. However as noted above, such an approach may have several limitations, in particular for an IS literature search where keywords are often related to specific technologies.

Keyword searching presents a classic cold-start problem for the novice researcher; how can one identify the applicable keywords for an unknown domain. The best source for keywords is, of course, the literature base for the domain and all articles reviewed should be read with an eye for potential keywords. Locating the first article can, however, be a considerable challenge. The Association for Computing Machinery (ACM) classification system (http://www.acm.org/class/1998/homepage.html) and MIS Quarterly Roadmap (http://www.misq.org/roadmap/code/level2/h.ht$\underline{\mathrm{ml}}$ ) offer the novice researcher a workable starting point.

The keyword search should be just the initial, not the main step for a literature search. A common mistake by novice researchers, specifically in IS, is to assume that the keyword search yields all that is available from the literature. Clearly one of the aims of this paper is to address this misconception. The limited depth of the literature background is usually manifested by the use of only naïve keywords for the literature search. Novice IS researchers tend to stick to specific keywords when conducting their literature search. However, due to the nature of the IS field and the tremendous progress in technology, keywords of IS literature tend to have a limited life span. An example of this keyword evolution is way the term Manufacturing Resource Planning or Material Requirements Planning (MRP) systems in the 1970s-1980s became Enterprise Resource Planning (ERP) systems in the 1990s. The novice IS researchers may report that the theoretical issues surrounding ERP systems have limited evidence, not being aware that one may find an abundance of work conducted about similar issues with MRP systems.

Another issue with the keyword search process is the use of technology specific terms or 'buzzwords' that appear and disappear from literature. An example can be found in the term 'phishing' (i.e. phishing e-mail scam) from information security and assurance. The term 'phishing' is a form of computer crime. If a novice IS researcher attempts to learn more about the phishing phenomenon, searching using this keyword may provide little or no prior work in scholarly literature. However, attempting to generalize the term and avoiding use of buzzwords would reveal that much work was done in the area of computer crime that may be very valid and applicable (Webster \& Watson, 2002).

Although most buzzwords appear and disappear from the literature over time, the underlying theories and theoretical constructs are more stable (Robey, Boudreau, \& Rose, 2000). It is, therefore, necessary to go beyond keywords and use the backward and forward approaches, which can help researchers to follow models, theories, theoretical constructs, and research streams.

\section{Backward search}

The idea of backward and forward search originated from Webster and Watson's (2002) article where they propose conducting backward and forward lookout of IS literature. This section and the following one will elaborate on such approaches by providing a step by step technique on how to conduct it in order to achieve higher quality literature search results, i.e. more effective results.

Using an effective keyword search will produce some initial insight into the domain one wishes to study. If these leads are from quality resources (see "Where to look for quality IS literature?" 
above on discussion of literature quality), additional steps should be used to advance the literature search and the researcher's knowledge about the phenomenon under study. One such step deals with backward literature search. The process of going backward in literature can be divided into three specific sub-steps: backward references search, backward authors search and previously used keywords.

Backward references search refers to reviewing the references of the articles yielded from the keyword search noted above. For example, if one is studying the construct of computer selfefficacy, hopefully in their keywords search the researcher will stumbled upon Compeau and Higgins (1995)'s pioneering article. Conducting a backward references search for computer selfefficacy, will mean to pull out and review all the relevant references of Compeau and Higgins (1995)'s article such as Bandura (1977) or Barling and Beattie (1983) articles. Doing such backward references search provides researchers with the ability to learn more about the origins of the construct, theory, or model under study. Moreover, a second level backward references search should be done by pulling the 'references of the references'. Doing so will enable the researcher to extend his or her knowledge even deeper on the phenomenon under study. Additionally, it may also provide the researcher an ability to find inconsistencies in literature as well as cases where references and quotes might have been taken out of context. Following this approach a third, fourth, or more levels of backward references search can be done to expand even further the knowledge.

Backward authors search refers to reviewing what the authors have published prior to the article. Most researchers in the IS field tend to conduct studies within a rather narrow phenomenon domain. Thus, querying an author's prior work may yield fruitful information. For example, if one is studying the construct of end user computer satisfaction (EUCS) and came across Doll and Torkzadeh (1991)'s work, a backwards authors search would also yield additional studies that the two authors conducted that have led them to the development of the EUCS construct.

Previously used keywords refers to reviewing the keywords noted in the articles yielded from the keyword search noted above. For example, in articles related to the study of IS effectiveness there are several classical manuscripts (Grover, Seung, \& Segars, 1996; Pitt, Watson, \& Kavan, 1995; Srinivasan, 1985) that note the term measurement as an important keyword related to such work. As such, by looking at articles that carry the term "measurement" as a keyword in previous literature pieces, one may find additional fruitful manuscripts in the literature search on the subject of IS effectiveness.

\section{Forward search}

The third step in the process exploring the knowledge base for references about the phenomenon deals with forward literature search. Similar to the process of the backward literature search, the forward search can be divided into two specific sub-steps: forward references search, and forward authors search.

Forward references search refers to reviewing additional articles that have cited the article. For example, a forward reference search for Compeau and Higgins's (1995) article can be accomplished by conducting an electronic library database search for all articles that include either "Compeau" or "Higgins" in their citations. Doing so will enable to researcher to extend their knowledge even further by locating follow-up studies or newer developments related to the phenomenon under study.

Forward authors search refers to reviewing what the authors have published following the article. For example, a forward authors search for Compeau and Higgins's (1995) article can be accomplished by conducting an electronic library database search for all articles that include either "Compeau" or "Higgins" as the author. Doing so will enable the researcher to extend even more 
their knowledge about the authors by identifying improvements or new findings related to the phenomenon under study.

\section{How to Tell When You Are Done With the Literature Search?}

The literature search is an evolving process in which the researcher is "digging" into the literature by uncovering additional literature that may be applicable for the proposed study. Such a digging process was previously noted in several metaphors. Some of the key metaphors noted by IS scholars via the ISWorld LISTSERV include: "funnel (funneling in)", "concertina (narrowing and enlarging your search, like a concertina windbag)", and "lens (to focus readers)" (Metcalfe, 2002). Figure 4 illustrates these three key metaphorical approaches.

By default, the literature search process should continuously be done during the course of the study. As noted previously, the use of backward and forward literature search techniques should provide additional valid references as the search progresses. However, it may appear to novice researchers that this process is a never-ending one. From a practical perspective, one needs to stop the search and move on to the processing and writing (output) of the literature review. Thus, the question arises: "At what point should the process of gathering additional relevant literature end?"

Leedy and Ormrod (2005) noted that one common rule of thumb is that the search is near completion when one discovers that new articles only introduce familiar arguments, methodologies, findings, authors, and studies. Thus, when reading a new literature piece, if one "will get the feeling that 'I've seen this (or something similar to it) before"' (Leedy \& Ormrod, 2005, p. 82), it may suggest that the literature search is near completion. The end of the search can also be indicated when no new citations are discovered and articles cited in newly discovered literature have already been reviewed. In sum, as Webster and Watson (2002) observed: "You can gauge that your review is nearing completion when you are not finding new concepts in your article set" (p. 16).
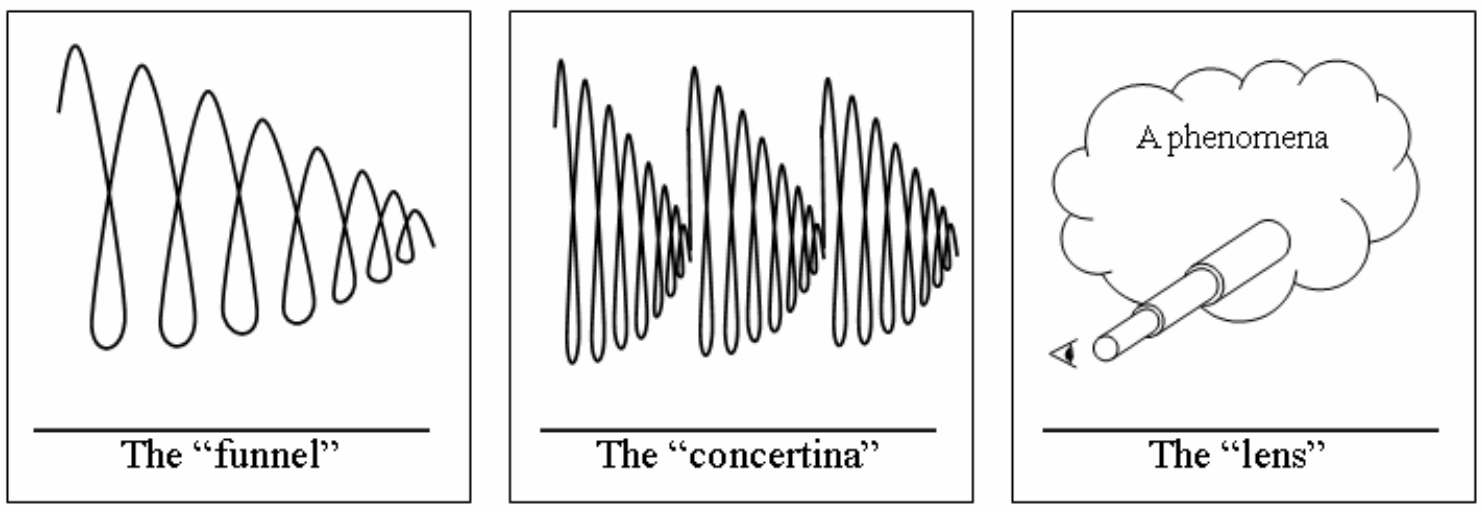

Figure 4: Key metaphors for literature search process

\section{Literature Review: Processing}

Locating applicable peer-reviewed articles is certainly a necessary condition for a literature review (J. Shaw, 1995); it is not a sufficient condition. The data contained in the sources identified must be processed into information that can serve as a foundation upon which new research can be built (Bem, 1995). Accomplishing this processing entails sophisticated cognitive activity. Although the methodology for evaluating the results of that cognitive activity has been explored rather thoroughly (Boote \& Beile, 2005; Hart, 1998), the ways and means for actually accomplishing the necessary processing is less clearly understood (Wu, 2005). How can the new or nov- 
ice researcher learn to effectively use the articles he or she locates to build the necessary foundation?

There is certainly no shortage of theories regarding human learning (Gagne, Briggs, \& Wager, 1992; Jonassen, Tessmer, \& Hannum, 1999). "Bloom's Taxonomy of Educational Objectives" (i.e. 'Bloom's Taxonomy') (Bloom, Engelhart, Furst, Hill, \& Krathwohl, 1956) has been shown to both effectively describe the learning process and offer meaningful insight into promoting development within the cognitive domain (Andrews \& Wynekoop, 2004; Manton, Turner, \& English, 2004; Noble, 2004; Zahn, Rajkumar, \& Zahn, 1996). Two concepts are integral to the Bloom's Taxonomy: cognitive capability is a developmental process that can be tracked through a series of steps, and each step of cognitive development can be identified by a number of specific types of behaviors. In effect, the Bloom's Taxonomy provides a set of sequential steps, each of which requires gradually more cognitively demanding activities that the researcher should do in developing the skill to transform the raw data of numerous literature sources into an effective literature review. The following sections provide a review of each of the Bloom's Taxonomy steps, with emphasis on the sequential process that a given step is as the foundation for the followed step.

\section{Know the Literature}

The knowledge level is commonly demonstrated by activities such as listing, defining, describing, and identifying. At the very least, the researcher must demonstrate that he or she has read the article and extracted meaningful information from it. Figure 5 presents an example of a citation that points to the literature but does not demonstrate mastery at the knowledge level. Although the citation certainly tells that Nunamaker, among others, had something to say about individual and group marks for in-group activities, the reader really don't have any idea what these references said.

Other research also indicates that individual and group marks should be combined in-group activities (Buchy \& Quinlan, 2000; Lim et al., 2003; Romano \& Nunamaker, 1998).

\section{Figure 5: Pointing at the literature}

Figure 6 presents this information in a manner that demonstrates knowledge - level mastery of the material. From this example it is clear that the citation provides some germane facts about the Buchy and Quinlan article: it was a report of some research, that the research was qualitative in nature, and that one of the conclusions from that qualitative research was that students participating in tutorial groups reported that the group activity made them more attuned to the learning process.

Buchy and Quinlan (2000) interviewed 36 students participating in tutorial groups. These interviews indicated that the students felt they were becoming more conscious of learning processes of both themselves and their peers.

Figure 6: Knowledge-level mastery

\section{Comprehend the Literature}

Comprehension is demonstrated by activities such as summarizing, differentiating, interpreting, and contrasting. At this level of mastery the researcher demonstrates that not only can he or she 
repeat what was included in the article but also knows the meaning and significance of the information being reported. Figure 7 illustrates a citation that presents un-interpreted bits of fact.

Han and Kamber (2001) suggest an evolution that moves from data collection and database creation, towards data management, and ultimately, data analysis and understanding.

Figure 7: Pre-comprehension level mastery

Although the citation in Figure 7 certainly indicates the point raised by Han and Kamber, it really does not demonstrate mastery over anything beyond a set of "buzz-words". The amplified citation displayed in Figure 8 demonstrates an understanding of the concepts presented by Han and Kamber.

Han and Kamber (2001) suggest an evolution that moves from data collection and database creation, towards data management, and ultimately, data analysis and understanding. For example, data processing is a base function enabling manipulation and aggregation of data, thus facilitating searching and retrieval.

\section{Figure 8: Comprehension-level mastery}

\section{Cognitive/construct-level}

Once the novice researcher starts reading scholarly literature it is often difficult for them to comprehend and thus apply the cognitive level addressed in such manuscripts. This is especially problematic for novice researchers that have extensive experience as practitioners but lack experience with scholarly research. There are several common terminologies used by scholars that warrant definition, elaboration, and clarification in order to help novice researchers comprehend scholarly work. As the following sub-sections will attempt to provide a review of such key terminology including discussion on what a theory is, in general, and provide a specific list of theories used in IS research. The following sub-section will discuss theoretical constructs and provide a specific list of constructs used in IS research. Finally, another sub-section will address theoretical models or frameworks and provide a specific list of models or frameworks used in IS research.

\section{Theory: Definition and Use in IS Literature}

The main essence of theory is to provide "an explanation of observed phenomena" (Kerlinger \& Lee, 2000, p. 11). Additionally, researchers suggest that theories are tentative explanations of reality and that each theory needs to be validated empirically to determine how well it represents reality (Kerlinger \& Lee, 2000). However, it appears that there are some inconsistencies in the literature about the definition of "theory" (Thomas, 1997). Kerlinger and Lee (2000) define theory as "a set of interrelated constructs (concepts), definitions, and propositions that present a systematic view of phenomena by specifying relationships among variables, with the purpose of explaining and predicting the phenomena" (p. 11). As such they noted that theory has three main components. The first component of theory includes propositions or hypotheses that are based on clearly defined and interrelated constructs (or concepts). The second component of theory includes a representation of a systematic view of phenomena by a notation of specific relationships among a set of constructs (or variables). The third component of theory includes an explanation of phenomena, mainly in order to help make predictions. Creswell (2003) defines theory as "a scientific prediction or explanation" (p. 120). However, literature suggests that theory is used differently in qualitative than in quantitative research (Sekaran, 2003). Quantitative research tends to 
use theory for deductive purposes or testing generalized perspective, or theory, of a specific phenomenon in a specific context. Qualitative research, on the other hand, tends to use theory for inductive purposes or developing a theory based on specific observed phenomenon (Sekaran, 2003). Leedy and Ormrod (2005) define theory as "verbal statement, visual model, or series of hypotheses offered to explain the phenomenon in question" (p. 155).

\begin{tabular}{|l|l|}
\hline \multicolumn{1}{|c|}{ Theory } & \multicolumn{1}{c|}{ Theory } \\
\hline - Absorptive capacity & - Knowledge-based theory of the firm \\
\hline - Actor-network theory & - Media richness theory \\
\hline - Adaptive structuration theory & - Organizational information processing theory \\
\hline - Administrative behavior, theory of & - Organizational knowledge creation \\
\hline - Agency theory & - Punctuated Equilibrium Theory \\
\hline - Argumentation theory & - Real options theory \\
\hline - Chaos theory & - Resource-based view of the firm \\
\hline - Cognitive dissonance theory & - Resource dependency theory \\
\hline - Cognitive fit theory & - Self-efficacy theory \\
\hline - Competitive strategy (Porter) & - SERVQUAL \\
\hline - Complexity theory & - Social exchange theory \\
\hline - Contingency theory & - Social cognitive theory \\
\hline - Critical social theory & - Social network theory \\
\hline - Diffusion of innovations theory & - Social capital theory \\
\hline - Dynamic capabilities & - Socio-technical theory \\
\hline - Evolutionary theory & - Soft systems theory \\
\hline - Expectation confirmation theory & - Structuration theory \\
\hline - Feminism theory & - Task-technology fit \\
\hline - Game theory & - Technology acceptance model \\
\hline - General systems theory & - Theory of planned behavior \\
\hline - Hermeneutics & - Theory of reasoned action \\
\hline - Illusion of control & - Transaction cost economics \\
\hline - Information processing theory & - Transactive memory theory \\
\hline - Institutional theory & - Unified theory of acceptance and use of technology \\
\hline
\end{tabular}

Source: Schneberger and Wade (2006): http://www.istheory.yorku.ca/ via ISWorld.net

\section{Figure 9: Main theories used in IS research, adopted from ISWorld}

A good metaphor provided to novice IS researchers about theory is the analogy to the house foundation. In order to have a solid structure, one must have a very solid foundation even if it cannot be seen. Therefore, it is observed in the literature that theory is often noted as the foundation of the research or theoretical background indicating the fundamental building block for any research. Figure 9 provides a list of common IS theories. It appears that in the context of IS there are theories that serve as a foundation for a single construct (i.e. Self-efficacy Theory) and there are theories that serve as foundation for whole model (i.e. TAM).

Representation of theory appears to be a challenging task. However, Creswell (2003) noted that researchers tend to represent theory in several forms. The first form of theory representation deals with a set of propositions or hypotheses and explanations of their interrelationships. A second form of theory representation, noted by Creswell (2003), deals with a set of causal relationships between constructs and variables. The third representation of theory is by visual models or conceptual maps. Such an approach is used primarily in a causal modeling to help researchers communicate their verbal theories into visual maps (i.e. theoretical or conceptual maps) that represent the interrelationships among constructs or variables (Creswell, 2003). These theoretical maps also often include influential directions noted with "+" or "-" among the arrows within the map. 


\section{Constructs/variables: Definition and Use in IS Literature}

Many researchers note the term "construct" similarly to the term "concept". However, there is a slight distinction between the two. Kerlinger and Lee (2000) noted that "a concept expresses an abstraction formed by generalization from particulars", whereas a construct is a concept with

\begin{tabular}{|c|c|}
\hline Construct & Construct \\
\hline - Acceptance of Quantitative System & - End-User Involvement \\
\hline - Adequacy of Training & - End-User Satisfaction With Computing Activity \\
\hline - Affect of Using Personal Computers & - Engagement \\
\hline - Application Systems Skills & - Enjoyment in Using A Software Package \\
\hline - Attending to Interpersonal Relations & - Enriching The Job \\
\hline - Attending to Production And Targeting Work Behavior & - Environmental Factors of Security \\
\hline - Attitude Toward Alternative Media & - Equity Perception in The Allocation of Is Resources \\
\hline - Attitude Toward Usage & - Executive Involvement in Management of IT \\
\hline \begin{tabular}{l|l|} 
& Behavioral Intention for Usage \\
\end{tabular} & - Executive Participation in Management of IT \\
\hline - Behavioral Problems & - Expectations About System \\
\hline \begin{tabular}{l|l|} 
Budget in Is Devoted to Training \\
\end{tabular} & - Experience With The System \\
\hline -Capabilities of The Planning System & - Extent of Boundary-Spanning Activities \\
\hline - Career Orientation & - Extent of Fulfillment of Key Planning Objectives \\
\hline - Career Satisfaction & - Facilitating Conditions -- Resources \\
\hline - Chargeback Information Use & - Facilitating Conditions -- Technology \\
\hline - Commitment to Ic Concept & - Facilitating Conditions of The Use of A Personal Computer \\
\hline $\begin{array}{l}\text { Communication in Meetings } \\
\end{array}$ & - Facilitating End-User Computing \\
\hline - Compatibility & $\begin{array}{l}\text { - Factors Contributing to Job Satisfaction } \\
\end{array}$ \\
\hline \begin{tabular}{l|l|} 
- & Compatibility of An Innovation With Experience \\
\end{tabular} & -Flow \\
\hline - Competitive Strategy & - Global User Satisfaction \\
\hline - Complexity of Personal Computers & - Health Related Behavior \\
\hline - Computer Abuse & - Image of Innovation Adopter \\
\hline - Computer Self-Efficacy & - Impact of Technology \\
\hline - Computer User Satisfaction & - Implementation Failure \\
\hline - Conflict As It Affects Systems Development & - Importance of Attributes of Is for Success \\
\hline - Conflict Resolution And Outcomes in Systems Development & - Importance of Job Roles \\
\hline \begin{tabular}{l|l|} 
- Coordination of End-User Computing \\
\end{tabular} & - Importance of Skills \\
\hline \begin{tabular}{l|l|}
- & Cost Variability \\
\end{tabular} & - Influence in Systems Development \\
\hline - Credibility of Computer System & - Information Center Support \\
\hline - Decentralization & - Intention to Leave Current Organization \\
\hline - Decision Making Satisfaction & - Interpersonal Communication About An Innovation \\
\hline - Demonstrability of Results With Innovation & - IT Structure \\
\hline - Design Considerations for System & - Job Complexity \\
\hline - Designer Perceptions of User Shortcomings & - Job Fit of Personal Computers \\
\hline - Desired Involvement in Computing Activity & - Job Satisfaction \\
\hline - Deterrent (To Computer Abuse) Certainty & - Job-Determined Importance (Need) for An Innovation \\
\hline - Deterrent (To Computer Abuse) Severity & - Level of System Utilization \\
\hline - Development of New Systems & - Long Term Consequences of Using A Personal Computer \\
\hline - Discrepancies Between Needs And Features & - Management Quality Interactions \\
\hline - Discussion Quality in A Meeting & - Measuring IS's Effectiveness \\
\hline - Duration of Cbis & - Microcomputer Playfulness \\
\hline - Ease of Use & - Motivational Factors \\
\hline \begin{tabular}{l|l|} 
Ease of Use of Innovation \\
\end{tabular} & - Nature of Work \\
\hline \begin{tabular}{l|l|} 
Ease of Use of Software Package \\
\end{tabular} & - Nonsalary Incentives \\
\hline - Economic Value Dimensions for Isd & - office Size Interactions \\
\hline - Efficacy & - office Type Interactions \\
\hline - Efficiency of Meeting Processes & - Organization Characteristics \\
\hline \begin{tabular}{l|l|} 
Employees Devoted to Computer-Related Training \\
\end{tabular} & - Organizational Commitment \\
\hline - End-User Computer Literacy & - Package Characteristics \\
\hline \begin{tabular}{l|l|} 
End-User Computing Satisfaction \\
\end{tabular} & \begin{tabular}{l|} 
- Participation in Design of Computer-Based Is Reports \\
\end{tabular} \\
\hline
\end{tabular}

Figure 10: Main constructs used in IS research, adopted from ISWorld 


\begin{tabular}{|c|c|}
\hline Construct (Cont.) & Construct (Cont.) \\
\hline -Participation in Systems Development & - Role Stressors \\
\hline - Peer Influences & -Skill in Software \\
\hline - Perceived Behavioral Control Over Usage & - Skill On A Task for Which An Innovation Could Be Used \\
\hline - Perceived Cohesion in Groups & - Social Factors Affecting Use of Personal Computers \\
\hline - Perceived Decision Making Purposes & - Socio-Political Value Dimensions for Isd \\
\hline - Perceived Disorientation & - Software Efficacy Beliefs \\
\hline -Perceived Ease of Use & - Source of Computer-Related Training \\
\hline $\begin{array}{l}\text { - Perceived Future Needs for Information Systems } \\
\end{array}$ & \begin{tabular}{l|l} 
Stage of Growth \\
\end{tabular} \\
\hline \begin{tabular}{l|l|} 
- Perceived Importance of Computer-Related Abilities \\
\end{tabular} & - Stages of Ic Evolution \\
\hline - Perceived Involvement in Computing Activity & - Status Effects Experienced in Meetings \\
\hline Perceived Job Characteristics & - Strategic Orientation of Business \\
\hline Perceived Management Support for An Innovation & - Strength of Management Message About An Innovation \\
\hline Perceived Medium Richness & - Stress \\
\hline Perceived Proficiency in General Is Knowledge & - Stressors \\
\hline - Perceived Proficiency in Is Product Knowledge & - Subjective Importance of A Task for Which An Innovation Could Be Used \\
\hline - Perceived Proficiency in Knowledge About The Organizational U & - Subjective Norm of Usage \\
\hline -Perceived Proficiency in Organizational Knowledge & - Success of Implementation \\
\hline -Perceived Proficiency in Organizational Skills & - Superior Influences \\
\hline - Perceived Proficiency in Technical Skills & - System Usage Related to Software Package \\
\hline - Perceived Usefulness & - Systems Analysis Availability \\
\hline - Perceived Usefulness of A DSS & - Task Characteristics \\
\hline - Perceived Usefulness of General Is Knowledge & \begin{tabular}{l|l|} 
- Task Equivocality \\
\end{tabular} \\
\hline - Perceived Usefulness of Is Product Knowledge & -Task Interdependence \\
\hline - Perceived Usefulness of Knowledge About The Organizational U & - Task-Technology Fit (Including Sub-Factors) \\
\hline Perceived Usefulness of MIS & - Team Work in A Meeting \\
\hline - Perceived Usefulness of Organizational Knowledge & - Technical Value Dimensions for Isd \\
\hline -Perceived Usefulness of Organizational Skills & -The Effects of A Technological Environment \\
\hline - Perceived Usefulness of Technical Skills & - Time of Implementation Interactions \\
\hline - Perceptions of Qualitative System & - Trialability of Other Innovations \\
\hline - Perceptions of Quality of Training & - Turnover Intentions Among Employees \\
\hline - Performance Impact of Computer Systems & - Type of Application \\
\hline - Personal Innovativeness Towards An Innovation & - Use And Satisfaction With The System \\
\hline - Physical Accessibility of An Innovation & - Use of Computer-Based Systems \\
\hline - Planning System Success & - Use of Different Training Methods \\
\hline - Preferred Form of Organizational Structure & - Use of Project Teams \\
\hline - Pressure to Use The System & - Usefulness \\
\hline Preventive Measures & - Usefulness of Software Package \\
\hline Processing Needs & - User Abilities \\
\hline - Productivity & - User Accountability \\
\hline - Progressive Use of It in The Firm & - User Authority \\
\hline Quality of Billing Information & - User Data Requirements \\
\hline - Quality of Ic Support Services & - User Information Satisfaction \\
\hline - Quality of Working Life & - User Involvement \\
\hline Relationships Between Job Characteristics And Data Required & - User Satisfaction With Ic \\
\hline - Relative Advantage of An Innovation & - Value Placed On Production And Services \\
\hline Reliance On Evaluation System Measures & - Visibility of Innovation \\
\hline Rival Explanations (For Computer Abuse) & - Voluntariness of Innovation Adoption \\
\hline - Role Ambiguity & - Work Attitudes And Intentions \\
\hline Role Clarity & - Work Environment Effects On Employees \\
\hline Role Conflict & \\
\hline
\end{tabular}

Source: Newsted, Huff, and Munro (2006): http://www.ucalgary.ca/ newsted/constructs.htm via ISWorld.net

\section{Figure 10: Main constructs used in IS research, adopted from ISWorld (Cont.)}

added meaning "deliberately and consciously invented or adopted for a special scientific purpose" (p. 40). It was also noted that many researchers (including some of the definitions provided above for theory), appear to suggest that constructs are also called "variables" (Kerlinger \& Lee, 2000). However, also here there is a slight distinction between the two. Kerlinger and Lee noted that "a variable is a property that takes on different values" (p. 40) or appears to be observable "when operationally defined" (p. 54). Whereas a construct is a type of variable that is "unobservable" 
(Kerlinger \& Lee, 2000, p. 54). Thus, in order to represent a construct, researchers proposed a special expression to indicate such unique type of unobserved variable by using the term "latent variable". A latent variable is a scientific representation of a construct that "can only be assessed indirectly" (Meyers, Gamst, \& Guarino, 2006, p. 28). From both the definition of construct and latent variables it is apparent that there is no direct way of measuring a construct, however, an indirect way to measure should exist. Meyers et al. (2006) noted that in research, constructs or latent variables can be indirectly measured "based on a weighted combination or composite of multiple measured variables" (p. 30). (For additional discussion about concepts, constructs and variables refer to Kerlinger and Lee (2000) chapter 3 "Constructs, Variables, and Definitions" as well as Meyers et al. (2006) pages 28-31). Figure 14 provides a list of commonly used constructs in IS literature.

\section{Models/frameworks: Definition and Use in IS Literature}

A model or theoretical framework is a generalized type of theory that indicates relationships between constructs or latent variables. Hart (1998) suggested that models are generalized theories that "enable more things to be explained using a unified approach" (p. 83). Therefore, it is common to see in IS literature the use of the term "model" synonym to the term "theoretical framework."

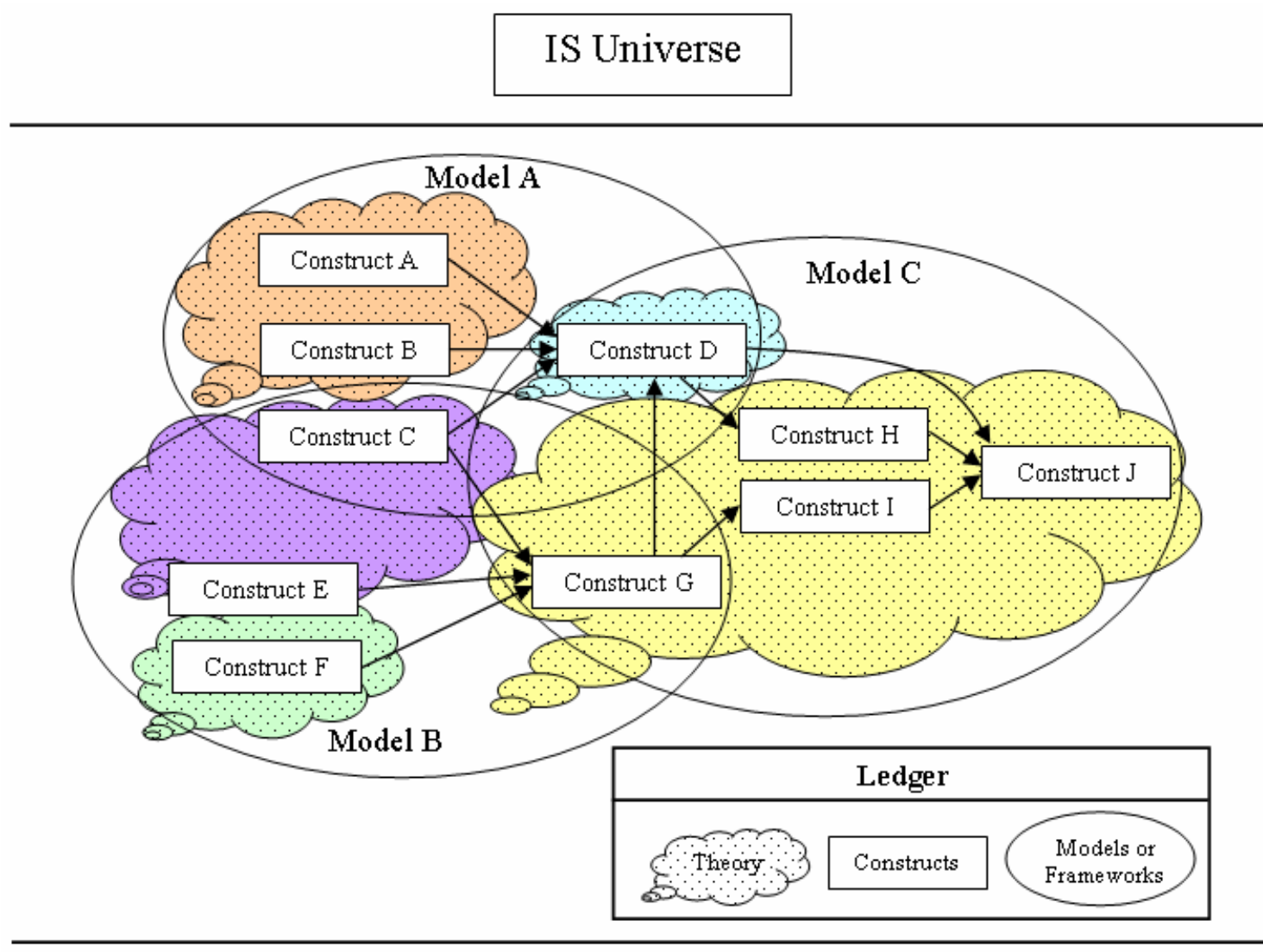

Figure 11: IS universe, models/frameworks, and constructs

Sekaran (2003) noted that "a theoretical framework is a conceptual model for how one theorizes or makes logical sense of the relationships among the several factors that have been identified as important to the [research] problem" (p. 87). Sekaran defined models or theoretical frameworks as "a logical development, described, and explained network of associations among variables of 
interest to the research study" (p. 97). Moreover, he noted that a model or "theoretical framework elaborates the relationships among the variables, explains the theory underlying these relations, and describes the nature and direction of the relationship" (p. 97). Additionally, he noted that models and theoretical framework are used to conceptualize a phenomenon by suggesting influences or relationships among constructs or variables. Figure 11 provides a visualization of the IS universe including representation of how theories, constructs, and models or theoretical frameworks are interconnected. The discussion of theoretical framework/models and constructs is key, because during the literature comprehension process researchers should "identify the variables that might be important as determined by previous research findings... [and] in addition to other logical connections that can be conceptualized, forms the basis for the theoretical model" (p. 97).

\section{Apply the Literature}

Application is demonstrated by activities such as demonstrating, illustrating, solving, relating, and classifying. In the context of the literature review, application is most directly revealed by the two-step process of: a) identifying the major concepts germane to the study and b) placing the citation in the correct category. Table 1, adapted from Webster and Watson (2002), illustrates the activities necessary to demonstrate mastery at the application level following the concept-centric approach discussed previously.

Table 1: Application-level mastery

\begin{tabular}{|l|c|c|c|c|}
\hline & Concept 1 & Concept 2 & $\ldots$ & Concept $\mathrm{n}$ \\
\hline Article 1 & $\mathrm{X}$ & & & $\mathrm{X}$ \\
\hline Article 2 & & $\mathrm{X}$ & & $\mathrm{X}$ \\
\hline$\ldots$ & & $\mathrm{X}$ & $\mathrm{X}$ & \\
\hline Article $\mathrm{n}$ & & $\mathrm{X}$ & \\
\hline
\end{tabular}

\section{Analyze the Literature}

Analysis is demonstrated by activities such as separating, connecting, comparing, selecting, and explaining. In essence, analysis entails identifying why the information being presented is of importance. Figure 12 illustrates a citation that presents the facts from the literature without the necessary analysis.

Data mining is the analyzing and interpretation of large amounts of information. Through analyzing vast amounts of data it is possible to find patterns, relationships and from these discoveries it is possible to make correlations (Chen \& Liu, 2005).

\section{Figure 12: Knowledge without analysis}

Left unanswered by this citation is an insight into why it would be of any interest or value to find patterns and relationships in order to make correlations. Figure 13 presents a modification to the citation that does provide that analysis. 
Data mining is a process of discovering new knowledge by using statistical analysis to identify previously unsuspected patterns and clustering in large data sets (Chen \& Liu, 2005).

\section{Figure 13: Analysis-level mastery}

\section{Synthesize the Literature}

Synthesis entails activities such as combining, integrating, modifying, rearranging, designing, composing, and generalizing. The essence of synthesis is to assemble the literature being reviewed for a given concept into a whole that exceeds the sum of its parts. Figure 14 illustrates a discussion in which facts are presented as almost a series of isolated "bullet points". Figure 15 presents that same information in a well-synthesized discussion in which the research from a number of sources is very effectively woven together.

The Digital Object Identifier (DOI) is an Internet-based system for global identification and reuse of digital content (Paskin, 2003). It provides a tracking mechanism to identify digital assets (Dalziel, 2004). The DOI is not widely employed across LOR and databases and is not universally adapted by content owners (Nair \& Jeevan, 2004). The DOI does not provide provision for assets to be tagged with copyright information (Genoni, 2004).

\section{Figure 14: Lack of synthesis}

One current DRM initiative, the Digital Object Identifier (DOI), is an Internet-based system for global identification and reuse of digital content, and provides a tracking mechanism to identify digital assets (Paskin, 2003; Dalziel, 2004). However, despite being integrated in learning object technologies, this DOI is not widely employed across LOR and databases, nor is it universally adapted by content owners (Nair \& Jeevan, 2004). Similarly, while most metadata schema enables assets to be tagged with copyright information, this method lacks technological enforcement (Genoni, 2004).

\section{Figure 15: Synthesis-level mastery}

\section{Evaluate the Literature}

Evaluation connotes activities such as assessing, deciding, recommending, selecting, judging, explaining, discriminating, supporting, and concluding. The essential evaluation in the literature review is to clearly distinguish among opinions, theories, and empirically established facts. Citations such as the one displayed in Figure 16 do not indicate if the material from the literature has been evaluated in any way.

Data mining has applicability to education as well as business (Sanjeev, 2002; Ma et al., 2000; Glance et al., 2005; Abe et al., 2004; Liu et al, 2005).

Figure 16: Non-evaluated citations 
... the applications of data mining fall under the general umbrella of business intelli-gence. Case studies have reported implementation of data mining applications for: (1) Enrollment management (to help capture promising students) (Sanjeev, 2002); (2) Alumni management (to foster donations and pledges) (Ma et al., 2000); (3) Marketing analysis (to better allocate the marketing funds) (Glance et al., 2005); and (4) Mail campaign analysis (to judge its effectiveness and design new, better targeted mailings) (Abe et al., 2004). Based upon the similarity to applications within the business community, Liu et al (2005) speculated that data mining could also be used within the educational community for fraud analysis and detection.

\section{Figure 17: Citations demonstrating evaluation}

The material presented in Figure 17, on the other hand, does demonstrate an element of evaluation. The author clearly identifies the type of information being presented - case study reports in the first four citations, opinion in the fifth citation.

\section{Literature Review: Outputs}

Hart (1998) noted that the "literature review as a piece of academic writing must be clear, have a logical structure and show that you have acquired a sufficient range of skills and capabilities at the appropriate level" (p. 172). In order to produce such a piece of academic writing, novice researchers should learn about the proper development of argumentation coupled with issues associated with the actual writing of the academic piece, i.e. the literature review. Therefore, the following section provides a review of argumentation theory and provides examples for proper argument writing. Following, a discussion on some myths associated with writing and a discussion on suggestions for proper writing structure of the literature review are provided. Lastly, a summary of the impact of the body of literature as a whole on the proposed study is provided.

\section{Writing Arguments and Argumentation Theory}

Toulmin (1958) proposed a model for argumentation that is being used in the legal environment for the development of arguments toward case presentations in courts (Walton, 2006). Williams and Colomb (2003) suggested a similar approach of argumentation process when writing research manuscripts. The core of the argumentation theory is a problem that motivates the research study. The problem is addressed by a claim put forth by the study, combined by the support or a reason

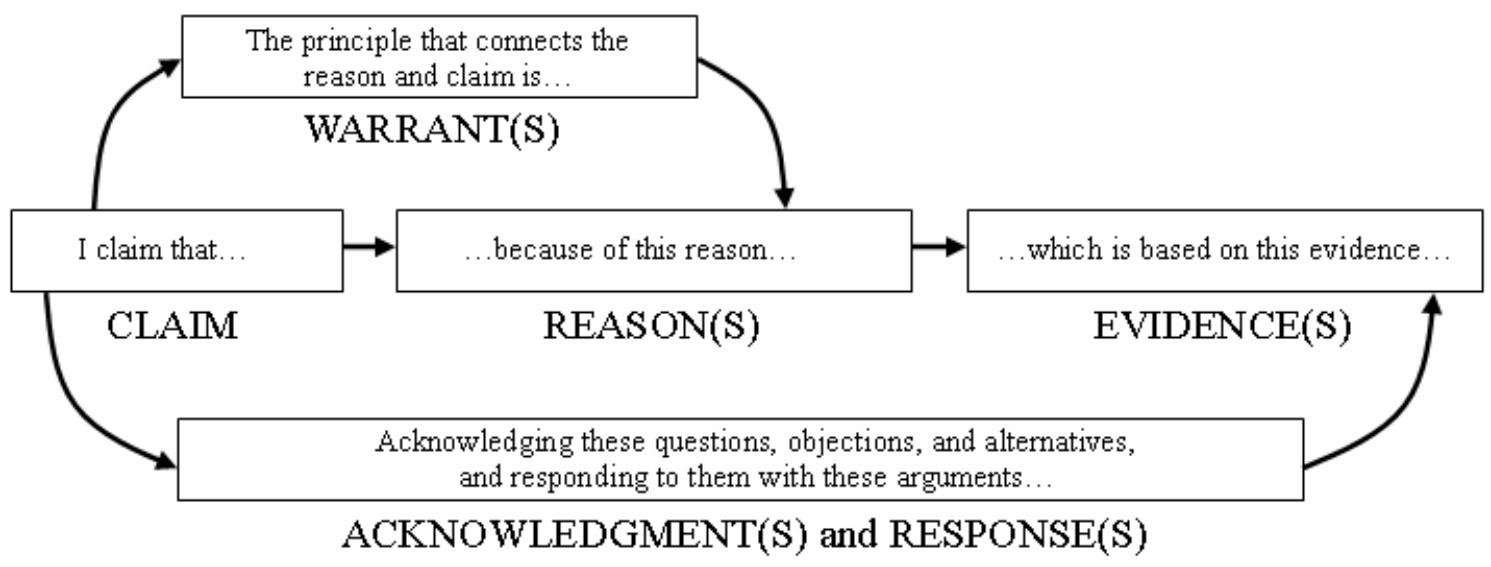

Figure 18: Williams and Colomb (2003, p. 42)'s argument model 
to such claim (or backing as noted by Toulmin). A claim is "an arguable statement" (Hart, 1998, p. 88). As such, a claim in the context of research study is an arguable statement that proposes a "solution to the problem" (Williams \& Colomb, 2003, p. 38). Hart (1998) suggests five different types of claims in research that include: claims of fact, claims of value, claims of concept and claims of interpretation. He noted that "the range in the types of claims from which an argument can be constructed shows that almost everything is arguable" (Hart, 1998, p. 89).

In order to anchor the argument processes around a proposed problem, Williams and Colomb (2003) suggest using evidence and warrants (or qualifiers and warrants as noted by Toulmin). Hart (1998) defines evidence as information and/or "data used to support the claim" (p. 88). Williams and Colomb (2003) noted that reasons are different from evidences in the fact that reasons are things people construct in their mind in order to provide rational for the argument, while evidences are the facts available somewhere that one can point to in order to anchor the argument. Additionally, Hart (1998) defined warrant (or permit) as "an expectation that provides the link between the evidence and the claim" (p. 88). Williams and Colomb noted that warrants are a somewhat difficult issue to comprehend. However, they noted that a warrant should consist of two parts "one part names a general circumstances...the second part states a general conclusion that [one] can infer from that circumstances" (pp. 184-185). They provide the following example to illustrate the structure of argument: "when an institution has its most eminent faculty teach first-year classes, it can justly claim that it puts its educational mission first [warrant]. We have tried to make our undergraduate education second to none [claim] by asking our best researchers to teach first-year students [reason]. For example, Professor Kinahan, a recent Nobel Prize winner in physics, is now teaching Physics 101 [evidence]" (p. 41).

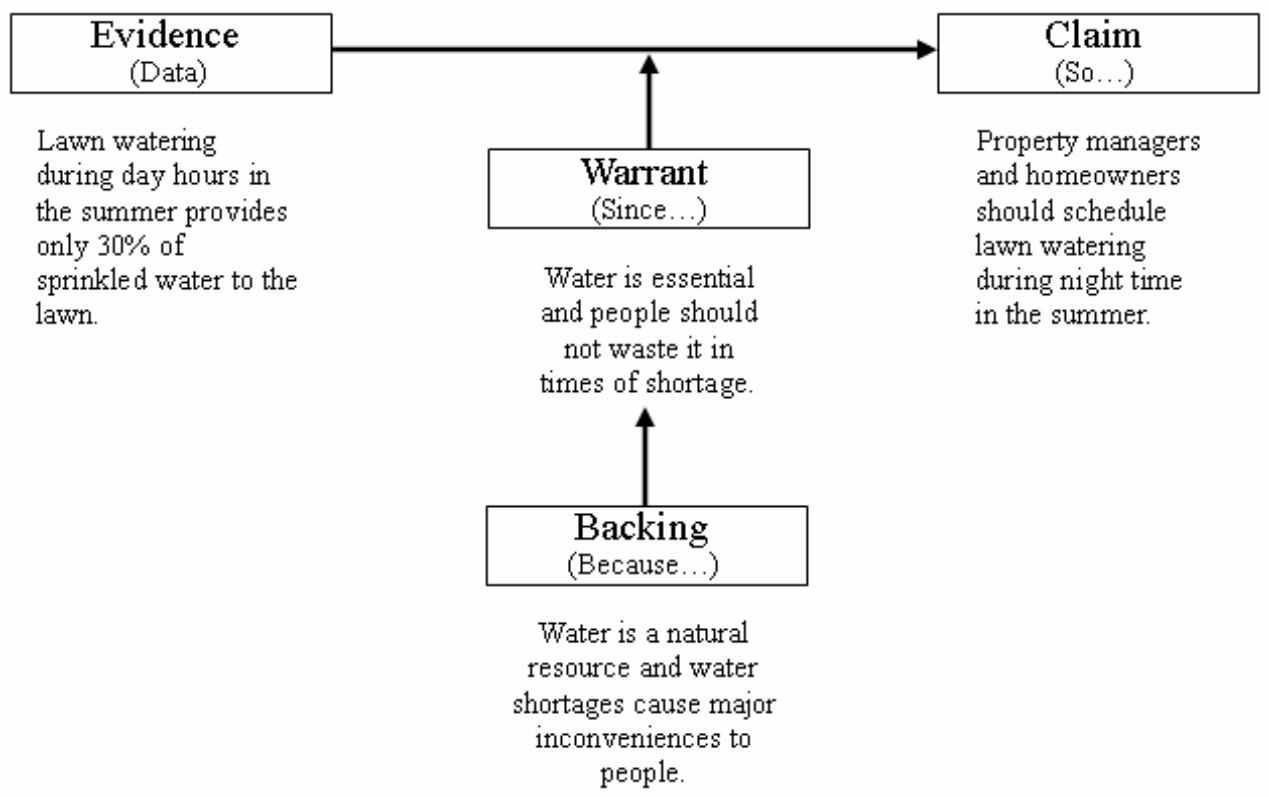

Figure 19: Toulmin (1958)'s structure of an argument, adopted from Hart (1998)

Figure 18 provides an overview of the argument model proposed by Williams and Colomb (2003). A proper argument process should follow the sequence of: "[claim] because of [reason] based on [evidence]" whereas a warrant serves to "connect a claim and it's supporting reason" ( $p$. 41). Figure 19 provides another example of the argument model, this one proposed by Toulmin (1958). Both examples share several similarities, however, the Williams and Colomb (2003) model uses the claim as the initial step in the argumentation process, whereas the Toulmin (1958) 
model uses the claim as the ending step in the argumentation process. Both argument methodologies are equally valid, therefore, novice IS researchers can adopt either model in their writing structure of the literature review section. Additionally, Figure 20 provides a review of the key points needed to be considered when writing the literature review in order to develop a sound argument following the guidelines propose by Hart (1998).

- Structure use a reliable structure that is explicit following proper argumentation.

- Definition define the terms you will use carefully with clear examples and backed by quality peer-reviewed sources.

- Reasons provide reason for everything you have included as support.

- Assumptions substantiate your assumptions; do not leave them as implicit. Use only reliable assumptions that are free of subjective judgment and are based on valid reasoning.

- Fallacies avoid fallacies, such as generalization, abstraction and misplaced concreteness.

- Evidence use only reliable documented evidence from quality peer-review sources that is legitimate and relevant, not trivial.

Figure 20: Criteria for a sound argument adopted from Hart (1998)

\section{Writing the Literature Review}

Most novice researchers find it difficult to write the literature review itself and blame it mainly on a list of myths (Troyka, 1993). Such list of myths about the difficulties in writing includes the claim that "writers are born not made", "writers have to be 'in the mood" to write", "writers do not have to revise", and that "writing can be done at the last minute" (pp. 48-49). To address these myths, Troyka noted that most writers were not born natural writers and that "being a good writer means being a patient writer" (p. 49), while Hart (1998) noted that "not many people find writing easy... [although] writing has difficulties, it is not something that only other people can do. Writing is something that most of us can do if we persevere" (p. 184). Additionally, Troyka (1993) notes that due to deadlines, most writers can't afford to wait for the 'mood' in order to produce their work. Moreover, writers must revise their work constantly in order to ensure the readers can understand their intended meaning clearly.

Writing the literature review should provide the reader with what the researcher did during the literature review input (see main section above) and what s/he has learned during the literature review processing (see main section above). As such the literature review will demonstrate to the reader the quality of the literature used to build the review. Moreover, Hart (1998) noted that the literature review will demonstrate to the reader "how you have extracted the main points from the literature by undertaking analysis, and how you have reconstructed the main idea in your own words by providing a critical synthesis" (p. 183). Thus, it is important to note that a quality academic literature review piece requires both time and effort to produce "a coherent piece of text" (p. 184). However, most novice researchers find it extremely difficult to put their ideas in writing as they experience problems with academic writing. Table 2 provides a review of three of such common problems with possible causes along with proposed solutions.

Hart (1998) suggested developing a plan of action when writing the literature review. The plan should include pre-writing and literature review structure (i.e. an outline), allocating appropriate evidences for each section, developing the first draft, allocating appropriate time for revising the draft, and writing the final draft. 
Table 2: Writing problems and solutions adopted from Hart (1998)

\begin{tabular}{lll}
\hline Problem & Possible cause(s) & Solution(s) \\
\hline Lack of time. & $\begin{array}{l}\text { Especially for part-time stu- } \\
\text { dents, life makes many de- } \\
\text { mands. }\end{array}$ & $\begin{array}{l}\text { Time management. } \\
\text { Make writing a part of your } \\
\text { personal leisure time. } \\
\text { Socialize family and friends } \\
\text { to recognize that your aca- } \\
\text { demic writing work is impor- } \\
\text { tant. }\end{array}$ \\
$\begin{array}{ll}\text { Unfamiliar with different } \\
\text { styles, especially academic } \\
\text { writing. }\end{array}$ & $\begin{array}{l}\text { Familiar only with style used } \\
\text { in the workplace. } \\
\text { Lack of academic writing } \\
\text { background. }\end{array}$ & $\begin{array}{l}\text { Read different styles. } \\
\text { Work at understanding dif- } \\
\text { ferent conventions for differ- } \\
\text { ent situations. }\end{array}$ \\
& $\begin{array}{l}\text { Used to face-to-face commu- } \\
\text { nication. } \\
\text { Rarely use writing for argu- } \\
\text { ment and persuasion, hence } \\
\text { not familiar with tenses, the } \\
\text { possessive and grammatical } \\
\text { conventions. }\end{array}$ & $\begin{array}{l}\text { Writing short piece first. } \\
\text { Subdivide academic writing } \\
\text { (such as dissertation drafts) } \\
\text { into manageable sections. }\end{array}$ \\
& & \\
\hline
\end{tabular}

For empirical studies, Creswell (2003) suggested a model of writing the literature review based on five main sections: 1) an introduction that tells the organization of the literature review section; 2) the first topic to address the independent variable(s) proposed by the study; 3 ) the second topic to address the dependent variable(s) proposed by the study; 4) the third topic to address studies conducted on the independent variable(s) and the dependent variable(s); 5) a summary that highlight the key research studies relevant to the proposed study, their general findings that relate to the proposed study, and support for the need of additional research on the proposed topic.

A key issue related to the writing of the literature review deals with ethical issues associated with academic writing. Ethical decision making should be maintained by all students in their academic endeavors and writing. Hart (1998) suggested that researchers must use their sources properly when writing the literature review in order to avoid criticism of their work. Such proper use should ensure that no violations of academic writing standards or code of conduct exist. Figure 21 provides a list of the main academic writing standards or code of conduct violations and their definitions.

- Falsification misrepresenting the work of others.

- Fabrication presenting speculations or general claims of others as if they were facts.

- Sloppiness not providing correct citations.

- Nepotism citing reference of scholars that are not directly addressing the point that the citation is used for

- Plagiarism the act of knowingly using another person's work as passing it off as your own.

Figure 21: Hart (1998, p. 181)'s list of some academic writing standard violations 


\section{Summary of the Impact of the Body of Literature as a Whole on Your Study}

The literature review serves five major functions in a research endeavor. It is vital in establishing the current state of the BoK, including identifying where excess research exists (i.e. what is already know?) and where new research is needed (i.e. what is needed to be known?). The review also provides a solid theoretical foundation for the proposed study (related to "what is already known?"). It substantiates the presence of the research problem (related to "what is needed to be known?") and justifies the proposed study as one that contributes something new to the BoK. Finally, the review frames the valid research methodologies, approach, goals, and research questions for the proposed study.

In order to accomplish these functions the review must do more than just "point to the literature". An effective review must describe the major points contained in an article, interpret those points, classify the article's position in the BoK, explain the importance of the article, compare and contrast the findings and position of the article with other articles from the BoK, and evaluate the findings of the article in light of the rest of the BoK.

\section{Discussion}

\section{Summary of the Value of Effective Literature Review}

It was suggested that the real value of published research work "is in the dissemination of knowledge for use by others" (Barnes, 2005, p. 10). However, the value or importance of an effective literature review is in ensuring that the researcher demonstrates a full understanding of the BoK related to the phenomenon under study, while at the same time "should be explanatory and creative" (Webster \& Watson, 2002, p. 11). Moreover, an effective literature review should demonstrate a thorough/systematic examination of the existing BoK by following the three-stage process framework discussed above, while demonstrating clear distinctions among opinions, theories, and empirically established facts.

\section{Literature Review: Tips from the Field}

Conducting a literature review is not just a cognitive challenge; it is also a management challenge. Developing a foundation in the literature or a research project can easily entail reviewing well over 100 articles and books. Mining that number of items for gems of information applicable to the research being conducted, and keeping track of the sources of that information, can be a very daunting task.

Although there is certainly not a single right way to manage the literature review process - every experienced researcher probably has her or his own preferred techniques - the trail-and-error process of developing a management approach could be quite costly in time and effort for the novice researcher. As a starting point for the novice researcher, the following sections detail some "field-tested" answers to the following management questions: how to get the most out of reading the literature; how to manage the workflow of the review process; and how to know when the literature review is complete.

\section{Reading the literature}

It is important to remember that the literature is being read purposively - actually, for two purposes: to establish a context in the existing BoK for the research being conducted, and to point to additional literature sources. The following techniques have been found to be very helpful in promoting the type of active reading necessary for the process: 
1) Keep an annotated copy of all the articles, book chapters, or conference proceedings you read in both hardcopy and electronic format. It is unbelievably frustrating to need to refer back to an article and find you do not have ready access to it.

2) Highlight everything in the article that is applicable to your research, even if you don't think you will use the material. It is almost impossible to tell exactly what direction research will take, and it can be very frustrating and time consuming to try to re-locate information you are almost certain you found in a given paper.

3) Write notes to yourself about the article you are reading regarding issues, thoughts, or general comments such as "nice methodology for ...", "interesting definition of...," etc.

4) Write a brief (one to two paragraph(s)) annotated bibliography entry that encapsulates the essential points applicable to your research derived from the article. It is important to note that the annotated bibliography is specific to your research and is not the same as the abstract for the article, which summarizes the entire study.

5) As one reads literature, be sure to look for and circle any terms or expressions that might serve as keywords that would facilitate the forward or backward searching described earlier.

6) Remember, it is important to place each article in the context of the body of knowledge by identifying the applicable model(s), construct(s), theory(ies), and/or literature stream(s) (see section "Cognitive/construct-level" above). Annotate the applicable model(s), etc. on the front of the article.

\section{Managing the literature review process}

As is evident from the preceding sections, quite a large number of factors must be managed while conducting a literature review. The magnitude of the organizational challenge can often overwhelm the novice researcher. Several techniques have been field-tested by veteran researchers and found to be useful. A brief overview of some of these field-tested techniques follows.

The first technique in managing the literature review process deals with tracking the research path. In order to adequately explore the literature base, a number of electronic databases (Figure 2 ) must be searched on a number of different keywords and keyword combinations. A simple spreadsheet such as the one illustrated in Figure 22 can prove to be quite useful in ensuring full coverage of the search.

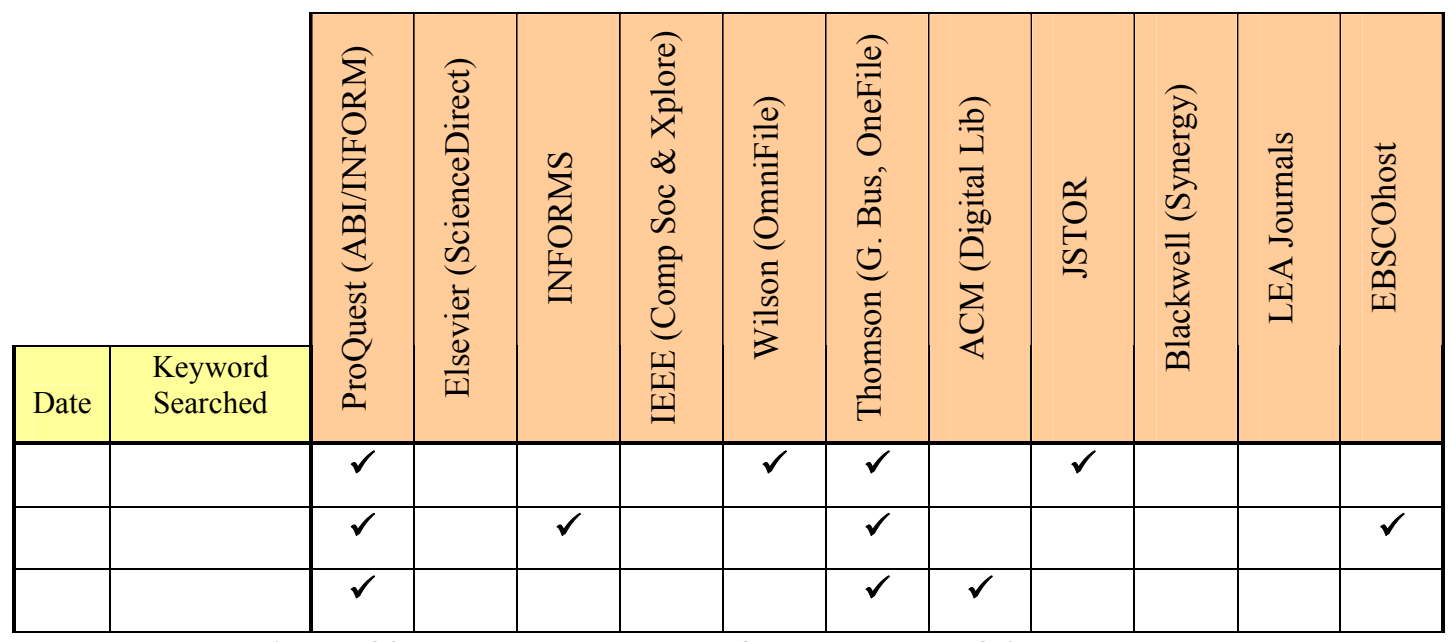

Figure 22: Worksheet to help full coverage of literature sources 
The second technique in managing the literature review process deals with filing the articles. Whether hardcopies and/or electronic copies of the annotated articles included in the literature review are retained, an effective filing system is essential. Within the filing system, it is important to be able to locate articles by author, title, applicable model/construct/theory/literature stream, and publication date. One approach is to ensure that each article is available both in electronic format as well as in hardcopy format. The management of the filing of both digital and physical should be parallel. For example, three inch binders can be used to store the physical articles with notation on the cover of the binder on the main content (e.g. "user satisfaction", "computer selfefficacy", etc.), whereas the digital library of such articles should match by having a folder in the hard-drive (or any other digital storage location) with the exact same notation of main contents. Inside each digital folder, articles can be saved by the last names of the authors and year of publication (i.e. "Levy_Ellis_2006.pdf"), whereas in the binders, the articles should be ordered alphabetically based on the authors' last names. Figure 23 illustrates the technique for physical and digital organization of articles during the literature review process.

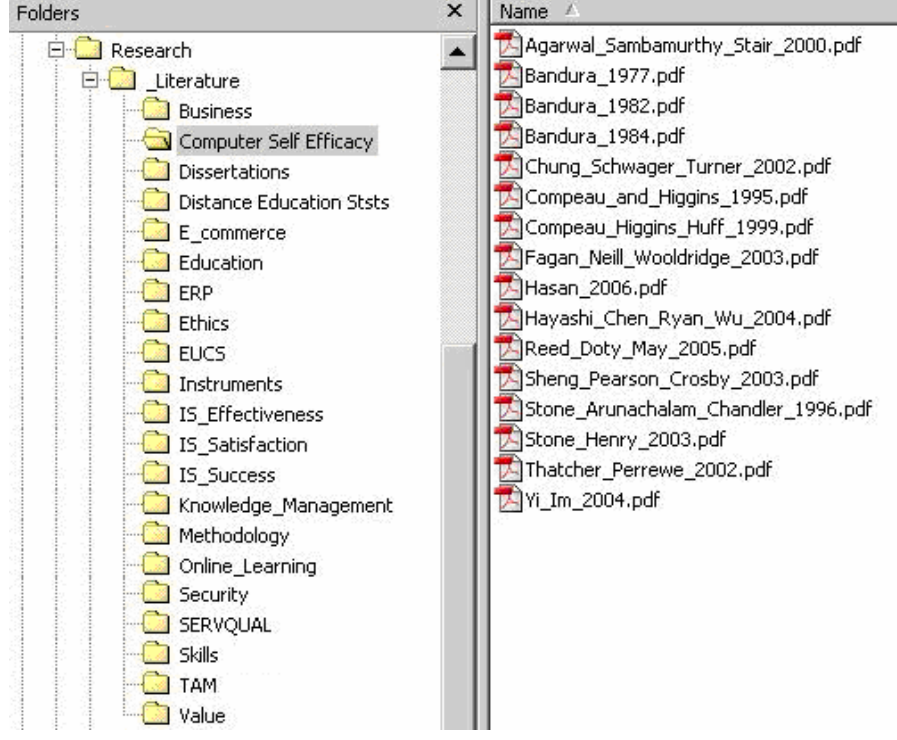

Digital

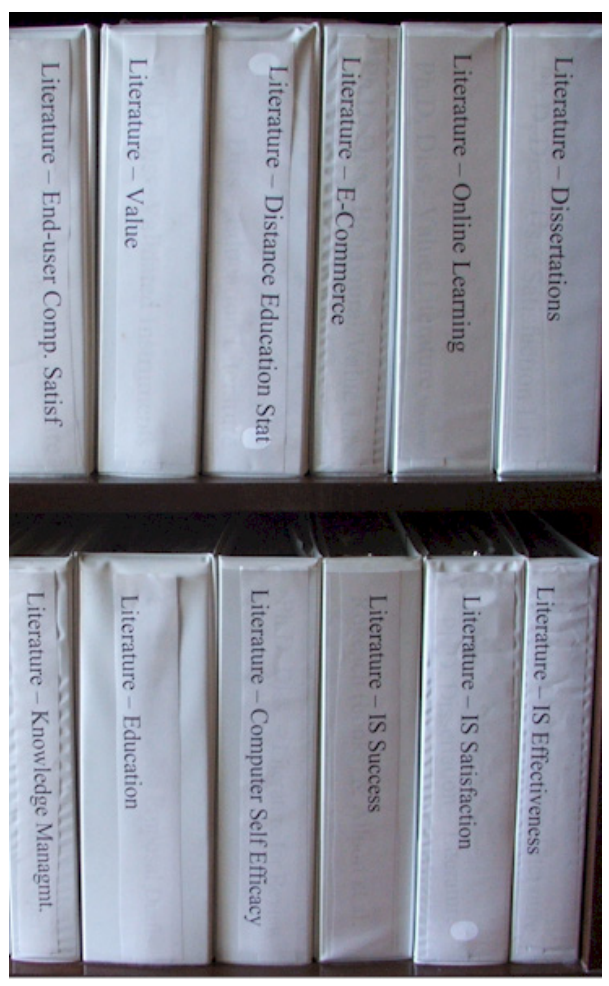

Physical

Figure 23: A technique for physical and digital organization of articles

The third technique in managing the literature review process deals with building an annotated bibliography. As mentioned in the preceding section, it is important to write a brief annotated bibliography entry for each item of literature included in your review. The annotated bibliography is most useful when each entry contains complete, well-written sentences that can be easily copied and pasted into the review of the literature and require minimal subsequent editing. The annotated bibliography should, of course, be linked with the article file to make it easy to find the complete article if additional information is needed. 
The fourth technique in managing the literature review process deals with automating the process. There are several commercial reference management products available. Programs such as EndNote $\AA$, ProCite ${ }^{\circledR}$, and Reference Manager ${ }^{\circledR}$ offer the capability of bringing organization to the search, storage, and retrieval of references. They also manage the very tedious task of formatting the citations and references in accordance with a wide range of publishing standards.

\section{When is the review completed?}

In a sense, a literature review continues until a study is completed; throughout the course of a study, one should remain alert to applicable research being reported. The best way to view the review is as an organic system that is constantly growing and changing as the study develops. Changes in methodology, addition of new constructs, and conflicting literature can all require further research. As such, the literature review, as a process, should not be viewed as completed until all the research associated with the study has been completed.

\section{Conclusions and Recommendations}

This paper presented a systematic framework for the construction of an effective literature review following the traditional data processing model. Following this model, the proposed framework suggests a three-stage approach to guide novice IS researchers in the development of a sound and effective literature review: 1) Inputs, 2) Processing, and 3) Outputs. The uniqueness of the proposed framework is in the methodological process that is presented enabling novice IS researchers the ability to decompose the task of the literature review into the three manageable stages. Additionally, specific examples from the IS field are provided in the discussion of the search methodology, quality literature sources from the IS field, and in the six-step processing approach that includes the theoretical IS universe, models/frameworks, and constructs. The theory of argumentation is discussed with examples of two different approaches for development of sound argumentation in the literature review writing. Finally, discussions on the value of the effective literature review, tips from the field, manageable steps on reading the literature, practical tips on how to actually manage the literature review, along with summary on when the literature review is practically completed are provided.

There are three groups of audiences that this paper aims to address. The first group includes doctoral students in IS or closely related programs, while the second group includes novice IS researchers. The attempt of this paper is to help novice IS researchers and IS doctoral students to better understand the value of effective literature review in research. Additionally, the paper aims to provide novice researchers with ways to understand what is required in order to produce a high quality literature review. With the three-stage process, novice researchers should be able to see how each stage is related to the next and understand how the whole process of the literature review is constructed to form the theoretical foundation for their proposed research. The second audience group includes professors who are teaching doctoral courses in IS or closely related programs. This paper can help professors by providing them a resource to guide their doctoral students on a systematic process for conducting effective literature review. Moreover, the paper can help such professors by providing them sources for additional readings (see reference list) on the subject of literature review, quality of sources, processing of the literature and classification, as well as sources of writing the actual review.

Future work in this endeavor may include expanding the process to provide additional examples from other fields. Such fields can include informing science, information technology education, computer technology education, computer science and more. Additionally, an expansion may include full writing samples of proposals, both positive and negative writing examples. 


\section{Acknowledgments}

The authors would like to thank Professor Eli Cohen, the Managing Editor of ISJ and Founder of Informing Science Institute as well as Professor Scott J. Lloyd, the ISJ Editor-in-Chief for their encouragements. Additionally, the authors would like to thank the six anonymous referees for their careful review, constructive comments, and valuable suggestions.

\section{References}

Andrews, C. P., \& Wynekoop, J. (2004). A framework for comparing IS core curriculum and IS requirements for accounting majors. Journal of Information Systems Education, 15(4), 437-450.

Bandura, A. (1977). Self-efficacy: Toward a unifying theory of behavioral change. Psychological Review, 84(2), 191-215.

Barling, J., \& Beattie, R. (1983). Self-efficacy beliefs and sales performance. Journal of Organizational Behavior Management, 5(1), 41-51.

Barnes, S. J. (2005). Assessing the value of IS journals. Communications of the ACM, 48(1), 110-112.

Bem, D. J. (1995). Writing a review article for psychological bulletin. Psychological Bulletin, 118(2), 172177.

Bloom, B. S., Engelhart, M. D., Furst, E. J., Hill, W. H., \& Krathwohl, D. R. (1956). Taxonomy of educational objectives: The classification of educational goals. New York: Longmans: D. McKay Co.

Boote, D. N., \& Beile, P. (2005). Scholars before researchers: On the centrality of the dissertation literature review in research preparation. Educational Researcher, 34(6), 3-15.

Compeau, D. R., \& Higgins, C. A. (1995). Computer self-efficacy: Development of a measure and initial test. MIS Quarterly, 19(2), 189.

Couger, J. D. (1989). Preparing IS students to deal with ethical issues. MIS Quarterly, 13(2), 211-220.

Creswell, J. W. (2003). Research design: Qualitative, quantitative, and mixed methods approaches (2nd ed.). Thousand Oaks, CA: Sage Publications.

Culnan, M. J. (1978). An analysis of the information usage patterns of academics and practitioners in the computer field: A citation analysis of a national conference proceedings. Information Processing \& Management, 14(6), 395.

Davis, F. D. (1989). Perceived usefulness, perceived ease of use, and user acceptance. MIS Quarterly, 13(3), 319-341.

Davis, F. D., Bagozzi, R. P., \& Warshaw, P. R. (1989). User acceptance of computer technology: A comparison of two theoretical models. Management Science, 35(8), 982-1004.

Davison, R. M., Vreede, G.-J. de, \& Briggs, R. O. (2005). On peer review standards for the information systems literature. Communications of the Association for Information Systems, 16(4), 967-980.

DeLone, W. H., \& McLean, E. R. (1992). Information system success: The quest for the dependent variable. Information Systems Research, 3(1), 60-95.

DeLone, W. H., \& McLean, E. R. (2003). The DeLone and McLean model of information systems success: A ten-year update. Journal of Management Information Systems, 19(4), 9-30.

Doll, W. J., \& Torkzadeh, G. (1991). The measurement of end-user computing satisfaction: Theoretical and methodological issues. MIS Quarterly, 15(1), 5.

Gagne, R. M., Briggs, L. J., \& Wager, W. W. (1992). Principles of instructional design (4th ed.). Fort Worth, TX: Harcourt Brace Jovanovich College Publishers.

Grover, V., Seung, J. R., \& Segars, A. H. (1996). Information systems effectiveness: The construct space and patters of application. Information \& Management, 31(4), 177-191. 
Hardgrave, B. C., \& Walstrom, K. A. (1997). Forums for MIS scholars. Communications of the ACM, 40(11), 119-124.

Hart, C. (1998). Doing a literature review: Releasing the social science research imagination. London, UK: Sage Publications.

Hozack, W. J., Ranawat, C., \& Rothman, R. H. (2003). Corporate sponsorship and research: Impact and outcome. The Journal of Arthroplasty, 18(8), 953-953.

Iivari, J., Hirschheim, R., \& Klein, H. K. (2004). Towards a distinctive body of knowledge for information systems experts: Coding ISD process knowledge in two IS journals. Information Systems Journal, 14(4), 313-342.

Jonassen, D. H., Tessmer, M., \& Hannum, W. H. (1999). Task analysis methods for instructional design. Mahwah, NJ: Lawrence Erlbaum Associates.

Katerattanakul, P., Han, B., \& Hong, S. (2003). Objective quality ranking of computing journals. Communications of the ACM, 46(10), 111-114.

Kerlinger, F. N., \& Lee, H. B. (2000). Foundations of behavioral research (4th ed.). Holt, NY: Harcourt College Publishers.

Kock, N., Davison, R., Clarke, R., \& Loch, K. (2000). IS research ethics (panel session): Defining ethical, barely ethical, and unethical behavior. Proceedings of the Twenty First International Conference on Information Systems, Brisbane, Queensland, Australia

Laband, D. N., \& Piette, M. J. (2000). Perceived conduct and professional ethics among college economics faculty. American Economist, 44(1), 24-34.

Leedy, P. D., \& Ormrod, J. E. (2005). Practical research: Planning and design (8th ed.). Upper Saddle River, NJ: Prentice Hall.

Lowry, P., Romans, D., \& Curtis, A. (2004). Global journal prestige and supporting disciplines: A scientometric study of information systems journals. Journal of the Association for Information Systems, $5(2), 29-75$.

Manton, E., Turner, C. T., \& English, D. (2004). Testing the level of student knowledge. Education, 124(4), 682-687.

Mason, J. B., Bearden, W. O., \& Richardson, L. D. (1990). Perceived conduct and professional ethics among marketing faculty. Academy of Marketing Science. Journal, 18(3), 185-197.

Metcalfe, M. (2002, June 21). Metaphors for literature reviews (responses summary for ISWorld listserv email request).

Meyers, L. S., Gamst, G., \& Guarino, A. J. (2006). Applied multivariate research: Design and interpretation. Thousand Oaks, CA: Sage Publication.

Mylonopoulos, N. A., \& Theoharakis, V. (2001). Global perceptions of IS journals. Communications of the $A C M, 44(9), 29-33$.

Newton, I. (1676, February 5). Letter to Robert Hooke. Available at http://www.quotationspage.com/quotes/Isaac Newton/

Ngai, E. W. T., \& Wat, F. K. T. (2002). A literature review and classification of electronic commerce research. Information \& Management, 39(5), 415-429.

Noble, T. (2004). Integrating the revised Bloom's taxonomy with multiple intelligences: A planning tool for curriculum differentiation. Teachers College Record, 106(1), 193-211.

Peffers, K., \& Ya, T. (2003). Identifying and evaluating the universe of outlets for information systems research: Ranking the journals. JITTA : Journal of Information Technology Theory and Application, $5(1), 63-84$. 
Pitt, L. F., Watson, R. T., \& Kavan, C. B. (1995). Service quality: A measure of information systems effectiveness. MIS Quarterly, 19(2), 173-187.

Rainer, R. K., \& Miller, M. D. (2005). Examining differences across journal rankings. Communications of the $A C M, 48(2), 91-94$.

Robey, D., Boudreau, M.-C., \& Rose, G. M. (2000). Information technology and organizational learning: A review and assessment of research. Accounting, Management and Information Technologies, 10(2), $125-155$.

Saunders, C. (n.d.). IS world's MIS journal rankings. Retrieved April 5, 2006, from http://www.isworld.org/csaunders/rankings.htm

Sekaran, U. (2003). Research methods for business. A skill building approach (4th ed.). New York, NY: John Wiley \& Sons.

Sethi, V., \& King, W. R. (1998). Organizational transformation thought business process reengineering. Upper Saddle River, NJ: Prentice Hall.

Shaw, D. (1995). Bibliographic database searching by graduate students in language and literature: Search strategies, system interfaces, and relevance judgments. Library \& Information Science Research, 17(4), 327-345.

Shaw, J. (1995). A schema approach to the formal literature review in engineering theses. System, 23(3), 325-335.

Sorenson, O., \& Fleming, L. (2004). Science and the diffusion of knowledge. Research Policy, 33(10), 1615-1634.

Srinivasan, A. (1985). Alternative measures of system effectiveness: Associations and implications. MIS Quarterly, 9(3), 243-253.

Straub, D. W. (1989). Validating instruments in MIS research. MIS Quarterly, 13(2), 147-170.

Thomas, G. (1997). What's the use of theory? Harvard Educational Review, 67(1), 75-104.

Toulmin, S. E. (1958). The uses of argument. Cambridge, UK: University Press.

Troyka, L. Q. (1993). Simon and Shuster handbook for writers (3rd ed.). NJ: Prentice-Hall.

Venkatesh, V., \& Davis, F. D. (1996). A model of the antecedents of perceived ease of use: Development and test. Decision Sciences, 27(3), 451-482.

Venkatesh, V., \& Davis, F. D. (2000). A theoretical extension of the technology acceptance model: Four longitudinal field studies. Management Science, 46(2), 186-205.

Walstrom, K. A., Hardgrave, B. C., \& Wilson, R. L. (1995). Forums for management information systems scholars. Communications of the ACM, 38(3), 93-102.

Walton, D. (2006). Examination dialogue: An argumentation framework for critically questioning an expert opinion. Journal of Pragmatics, 38(5), 745-777.

Webster, J., \& Watson, R. T. (2002). Analyzing the past to prepare for the future: Writing a literature review. MIS Quarterly, 26(2), 13-23.

Whitman, M. E., Hendrickson, A. R., \& Townsend, A. M. (1999). Research commentary. Academic rewards for teaching, research, and service: Data and discourse. Information Systems Research, 10(2), 99-109.

Williams, J. M., \& Colomb, G. G. (2003). The craft of argument (2nd ed.). New York, NY: Longman.

Wu, M.-M. (2005). Understanding patrons' micro-level information seeking (MLIS) in information retrieval situations. Information Processing \& Management, 41(4), 929-947.

Zahn, S. B., Rajkumar, T. M., \& Zahn, C. J. (1996). Incorporation of student portfolios in the TQM classroom. International Journal of Instructional Media, 23(4), 327-340. 


\section{Biographies}

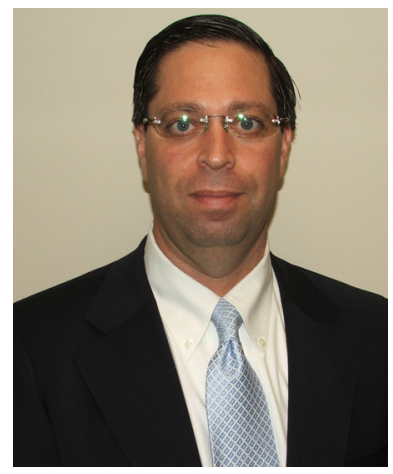

Dr. Yair Levy is an assistant professor of Management Information Systems at the Graduate School of Computer and Information Sciences at Nova Southeastern University. During the mid to late 1990s, he assisted NASA to develop e-learning systems. He earned his Bachelor's degree in Aerospace Engineering from the Technion (Israel Institute of Technology). He received his MBA with MIS concentration and Ph.D. in Management Information Systems from Florida International University. His current research interests include cognitive value of IS, of online learning systems, effectiveness of IS, and cognitive aspects of IS. Dr. Levy is the author of the book "Assessing the Value of eLearning systems". His research publications appear in the IS journals, conference proceedings, an invited book chapters, and encyclopedias. Additionally, he chaired and co-chaired multiple sessions/tracks in recognized conferences. Currently, Dr. Levy is serving as the editor-in-chief for the International Journal of Doctoral Studies (IJDS) and serving as an associate editor for the International Journal of Web-based Learning and Teaching Technologies (IJWLTT). Moreover, he is serving as a member of editorial review or advisory board of several refereed journals. Additionally, Dr. Levy has been serving as a referee research reviewer for numerous national and international scientific journals, conference proceedings, as well as MIS and Information Security textbooks. He is also a frequent speaker at national and international meetings on MIS and online learning topics. To find out more about Dr. Levy, please visit his site: http://scis.nova.edu/ levyy/

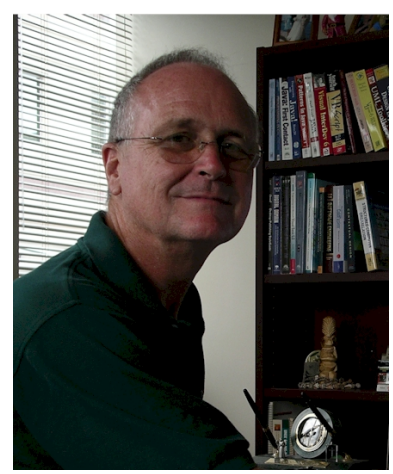

Dr. Timothy Ellis obtained a B.S. degree in History from Bradley University, an M.A. in Rehabilitation Counseling from Southern Illinois University, a C.A.G.S. in Rehabilitation Administration from Northeastern University, and a Ph.D. in Computing Technology in Education from Nova Southeastern University. He joined NSU as Assistant Professor in 1999 and currently teaches computer technology courses at both the Masters and Ph.D. level in the School of Computer and Information Sciences. Prior to joining NSU, he was on the faculty at Fisher College in the Computer Technology department and, prior to that, was a Systems Engineer for Tandy Business Products. His research interests include: multimedia, distance education, and adult learning. He has published in several technical and educational journals including Catalyst, Journal of Instructional Delivery Systems, and Journal of Instructional Multimedia and Hypermedia. His email address is ellist@nova.edu. His main website is located at http://www.scis.nova.edu/ ellist/ 